\title{
A comprehensive review of ultralow-weight proppant technology
}

\author{
Yong-Cun Feng ${ }^{1,2} \cdot$ Cheng-Yun Ma ${ }^{1,2} \cdot$ Jin-Gen Deng ${ }^{1,2} \cdot$ Xiao-Rong $\mathrm{Li}^{3} \cdot$ Ming-Ming Chu ${ }^{1,2} \cdot$ Cheng Hui $^{1,2}$. \\ Yu-Yang Luo ${ }^{1,2}$
}

Received: 12 December 2020 / Accepted: 5 January 2021 / Published online: 21 February 2021

(c) The Author(s) 2021

\begin{abstract}
Proppant plays a critical role in the exploitation of oil and gas, especially in the development of nonconventional oil and gas resources. Proppants are small spheres that have adequate strength to withstand high closure stresses to keep cracks open; therefore, hydrocarbon flows smoothly into the wellbore. However, traditional proppants are prone to settling in hydraulic fracturing operations, which seriously affects the operation effect. To this end, ultralow-weight proppants have been extensively employed in the petroleum industry. One of the widespread forms of ultralow-weight proppant application in the oil and gas industry is related to light density. Ultralow-weight proppants will provide substantial flow paths with a considerably high propped surface area and remarkably reduce fine generation and scaling. This paper presents a comprehensive review of over 50 papers published in the past several decades on ultralow-weight proppants. The purpose of this study is to provide an overview of the current ultralow-weight proppant development status in raw materials, manufacturing process, performance characteristics, hydrophobic and lipophilic capabilities, and field application to promote the research of new ultralow-weight proppants. Lastly, this study analyzes the current challenges and emphasizes the development direction of fractured proppants.
\end{abstract}

Keywords Proppant $\cdot$ Hydraulic fracturing $\cdot$ Gravel packing $\cdot$ Ultralow density $\cdot$ Hydrophobic modification

\section{Introduction}

In recent years, unconventional natural gas resources, which include shale gas, tight gas, coal bed methane, and methane hydrates, have become important energy sources (Sharma et al. 2012). However, great difficulties are encountered in the mining process, given that unconventional oil and gas resources have two major characteristics, namely, low permeability and high viscosity (Willberg et al. 2015). Hydraulic fracturing is one of the most popular techniques in oil fields to improve the conductivity of ultralow permeability

Handling editor: Liang Xue

Edited by Yan-Hua Sun

Cheng-Yun Ma

mcy0000@163.com

1 College of Petroleum Engineering, China University of Petroleum, Beijing 102249, China

2 State Key Laboratory of Petroleum Resources and Engineering, Beijing 102249, China

3 College of Safety and Ocean Engineering, China University of Petroleum, Beijing 102249, China reservoirs by injecting a pressurized fluid mixed with proppants (Man 2016). The fracturing process refers to injecting a viscous fluid at a certain pressure to break down a rock. Then, proppant slurries are pumped into the induced fracture to maintain it open; thus, the hydrocarbon can flow smoothly into the wellbore (Fig. 1) (Neog 2014). In accordance with raw materials, proppants can be divided into three main categories: rounded silica sand, gravel and resin-coated sands, and sintered and/or fused synthetic ceramic materials (Liang et al. 2015). On the basis of density difference, they can be classified into high-, intermediate-, lightweight-density (Abd El-Kader et al. 2020).

However, traditional fracturing proppants would have a fast-settling rate due to the high density (Han et al. 2016), which largely decreases the effect of hydraulic fracturing. To prevent high- or intermediate-density proppants from settling, additive agents are indispensable for the fracturing fluid (Lester et al. 2014). However, on the one hand, most additive agents are harmful to the environment due to their chemical toxicity (Fan et al. 2018); on the other hand, residual of high-viscosity cross-linked fracturing fluids could lead to severe permeability damage (Bestaoui-Spurr and Hudson 2017). Consequently, low-viscosity fluids or 


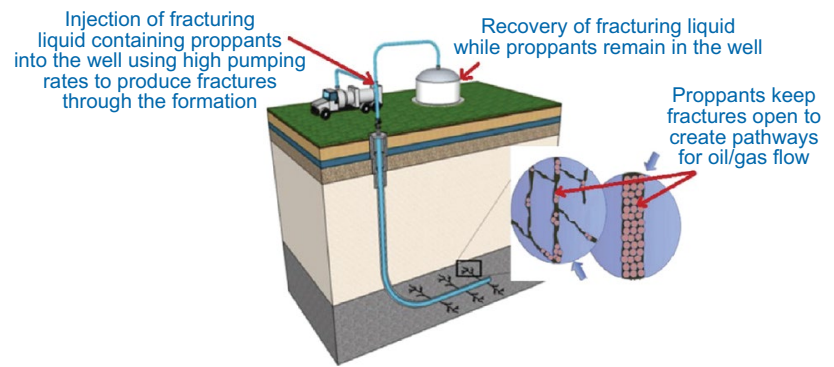

Fig. 1 Mechanism of fracture opening by using ceramic proppants with high sphericity and roundness and fused surface (Abd El-Kader et al. 2020)

slick water have largely been adopted in hydraulic fracturing treatments in unconventional reservoirs (Nguyen et al. 2013) in recent years. However, a problem with slick water is that common proppants tend to settle. A new proppant that is close to the density of fracturing fluid and can meet the requirements of hydraulic fracturing technology is urgently needed (Fan et al. 2018).

In addition to being essential materials in the fracturing process, proppants are also often used in sand control completion operations. Most offshore oil and gas fields are loose sandstone reservoirs and easily produce sand during the mining process (Deng et al. 2019b). Sand control completion is required to maintain long-term gas production (Stadulis 1995). Gravel pack sand control is regarded as the most effective sand control method (He et al. 2018), which is commonly used in complex reservoirs. Compared with other sand control methods, the gravel pack sand control method is more suitable for reservoirs with fine-silty sand or formations with a wide range of particle size distribution (Ma et al. 2020; Martch et al. 2012). In accordance with incomplete statistics, sand control wells using gravel packing account for nearly $90 \%$ of oil fields (Zhou and Sun 2016). The greatest problem currently is that the sand control costs account for $35 \%$ of the total completion cost (Deng et al. 2019a). The operation time of the gravel pack sand control method is approximately $10 \mathrm{~h}$ longer than others. In addition, for the gravel sand control method, the quality of gravel packing is difficult to guarantee (Zhou and Sun 2016), especially for large-reach and ultralong horizontal wells (Pucknell and Mason 1992). Compared with common proppants, the ultralow-weight (ULW) proppant is easy to be displaced and can obtain nearly $100 \%$ packing effectiveness during gravel sand control completion. With the development of various technologies, ULW proppants accounted for $50 \%$ of open-hole gravel packing operations in 2011 (Fig. 2) (Neto et al. 2012).

ULW proppants are usually $25 \%-60 \%$ lighter than commonly used sands but are sufficiently strong to withstand fracture closure stresses (Gu et al. 2015). Some of them are

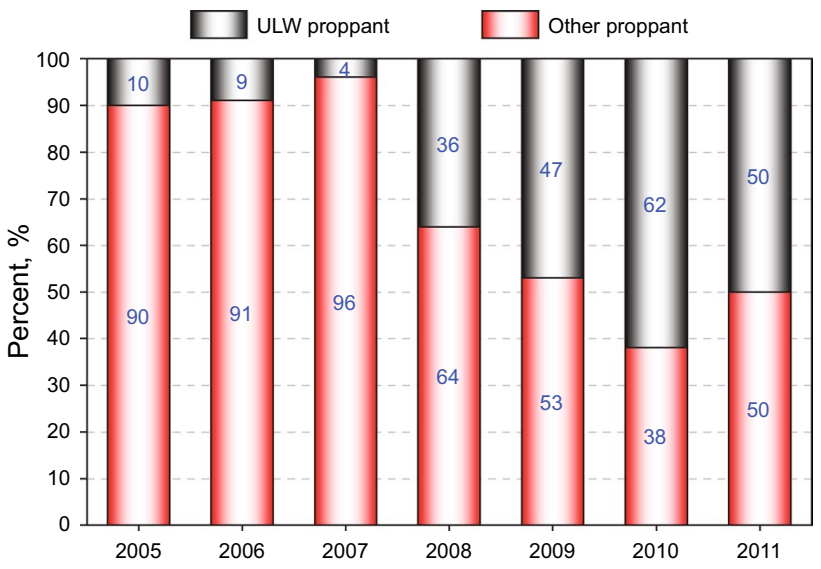

Fig. 2 Application status of ULW in open-hole gravel packing (Jardim Neto et al. 2012b)

made of polymers, polystyrene/graphite composites (Guo et al. 2013; Han et al. 2014), and resin-coated nutshell composites (Fan et al. 2018). In short, ULW proppants are becoming increasingly popular. This review aims to summarize the basic features and potential application of ULW proppants. The first part of this review will briefly discuss the basic parameters of ULW proppants, and the second part will address the ULW modification technology. The third part will summarize field application cases in recent years. To the best of the authors' knowledge, no recent review of the relative technologies of ULW proppants, including the basic performance of ULW proppants and advancements in the ULW proppant technology that has been developed in recent years, has been presented. This review cannot only help researchers have a new understanding of ULW proppants but also help in the wide application of ULW proppants in the field.

\section{ULW proppants}

A fracturing proppant whose bulk density is less than $1.5 \mathrm{~g} /$ $\mathrm{cm}^{3}$ and apparent density is approximately $2.5 \mathrm{~g} / \mathrm{cm}^{3}$ can be regarded as a ULW fracturing proppant (Wu 2013). On the one hand, it can reduce the amount of guar gum used in the fracturing fluid, which reduces the damage to a reservoir (Cheng and Li 2006); on the other hand, it can reduce the energy loss during the fracturing process and thus form a high-conductivity fracturing crack (Gao et al. 2015; Li 2013). Proppants with ultralow density, high closure pressure, and good heat resistance are urgently needed in the process of unconventional oil and gas resource exploitation. The ULW proppants reported in the literature (Table 1) is mainly divided into three categories in accordance with raw materials, including ULW-1 (organic polymer), ULW-2 


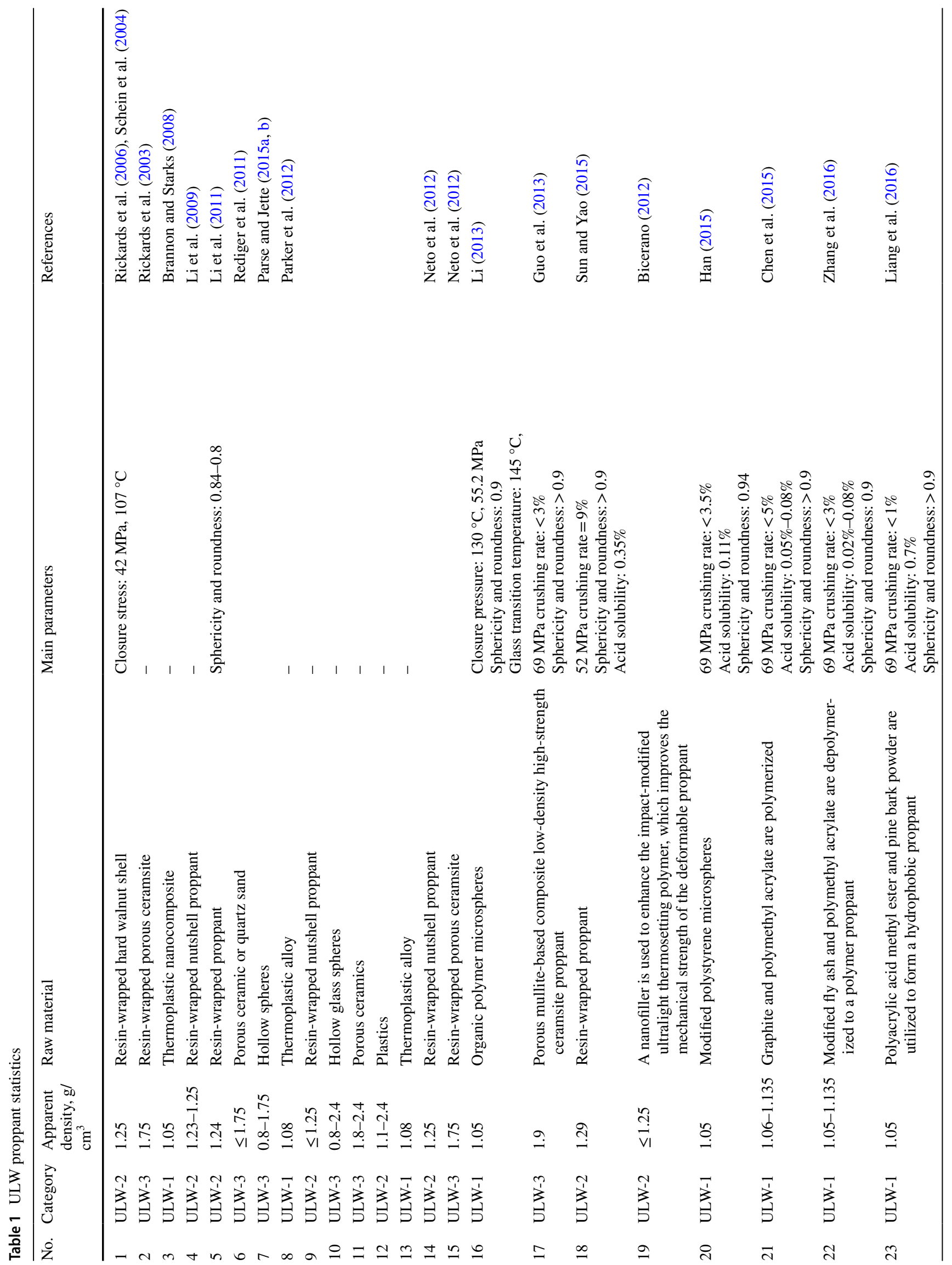




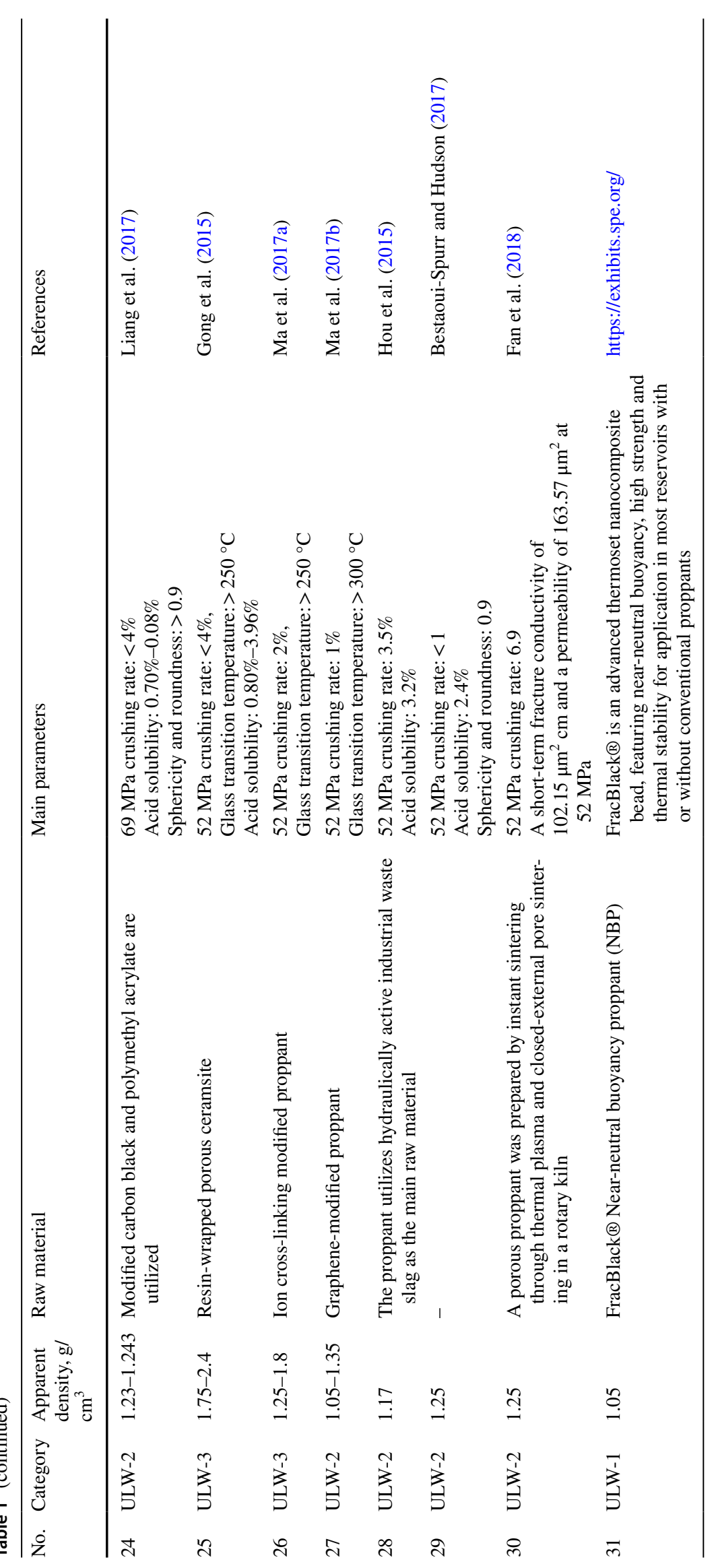


(impregnation of nutshells, coated), and ULW-3 (porous ceramsite coated with resin). Each type of proppant has its own advantages and disadvantages. They have been widely used in different conditions depending on geology, availability, prices, and government regulations. The following is a basic introduction to each proppant type.

\subsection{Basic properties of ULW proppants}

ULW-1 (Brannon et al. 2009; Brannon and Starks 2008) is a heat-treated nanopolymer microsphere with an apparent density of $1.05 \mathrm{~g} / \mathrm{cm}^{3}$, a glass transition temperature of approximately $145{ }^{\circ} \mathrm{C}$, a closure pressure of $45 \mathrm{MPa}$, and a size of 14/40 mesh and 40-80 mesh (Fig. 3). The acid solubility rate is less than $2 \%$, and the sphericity is greater than 0.9 . The disadvantage of ULW-1 is that it is prone to deformation compared with traditional fracturing proppants.

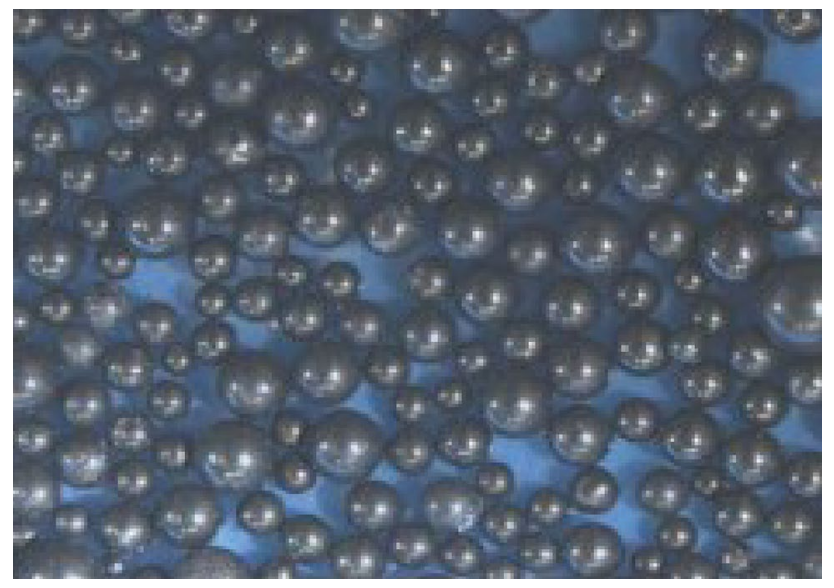

Fig. 3 ULW-1.05 ultralightweight proppant (Brannon et al. 2009)

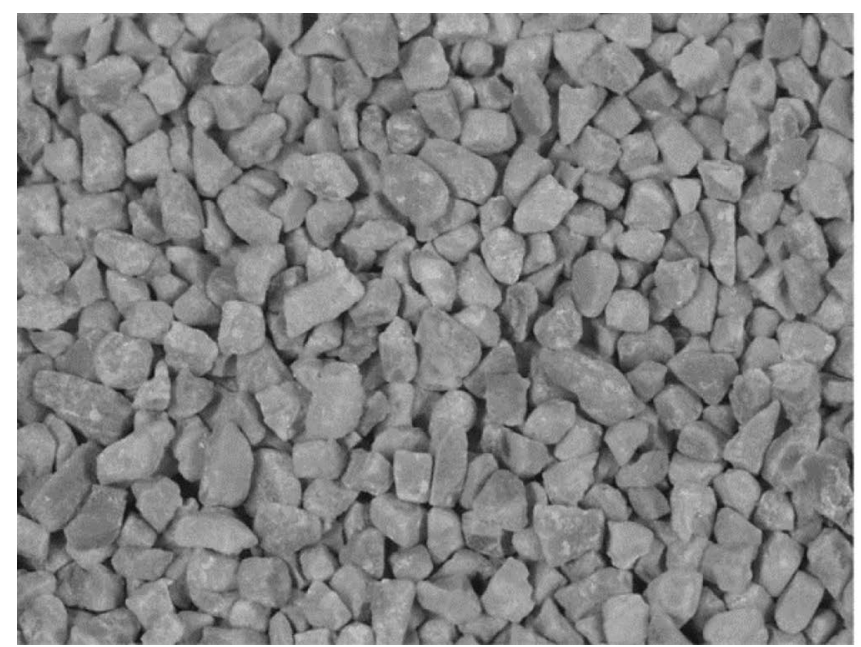

Zhang used graphite, fly ash, and reinforcing carbon black to polymerize with polystyrene to form a nanocomposite ULW polymer microsphere (Zhang et al. 2016). The glass transition temperature reached above $250{ }^{\circ} \mathrm{C}$, and the crush resistance was less than $2 \%$ at $52 \mathrm{MPa}$. Parker et al. also developed a new ULW proppant from thermoplastic aluminum alloys with stable chemical properties (Parker et al. 2012). However, it can only be applied to a reservoir with low closure pressure (approximately $7 \mathrm{MPa}$ ) because of the strength limit. The density of this proppant is approximately $1.05-1.08 \mathrm{~g} / \mathrm{cm}^{3}$.

ULW-2 (Bestaoui-Spurr and Hudson 2017; Han et al. 2016; Parker et al. 2012) is a highly angular particle (such as husks and walnut shells), which yields a high permeability at low closure stresses, and no fines are produced as stress increases (Fig. 4). The raw material is necessary to impregnate or wrap with resin to improve the closure stresses. The ULW-2 proppant has an apparent density of $1.25 \mathrm{~g} / \mathrm{cm}^{3}$. It can withstand closure stress of $42 \mathrm{MPa}$ at $79^{\circ} \mathrm{C}$ and $28 \mathrm{MPa}$ at $146{ }^{\circ} \mathrm{C}$.

ULW-3 (Coker and Mack 2013; Jardim Neto et al. 2012b; Rickards et al. 2006) is a porous particle, such as hollow glass microspheres and hollow spheres. It has the same surface roughness as conventional ceramic proppants, as shown in Fig. 5. This type of proppant has an average porosity of approximately $50 \%$ and can form a ULW proppant with a stereoscopic density of approximately $1.75 \mathrm{~g} / \mathrm{cm}^{3}$. The closing stress of $56 \mathrm{MPa}$ can be tolerated at $121{ }^{\circ} \mathrm{C}$. Nonetheless, this proppant type exhibits a tendency to produce fine particles, leading to the plugging of pores.

Table 2 compares the bulk density, bulk porosity, and sphericity of the above three proppants. ULW-3 is the heaviest proppant, whereas ULW-1 is the lightest. As shown in Fig. 6, ULW-1 is basically spherical, ULW-2 is polygonal,

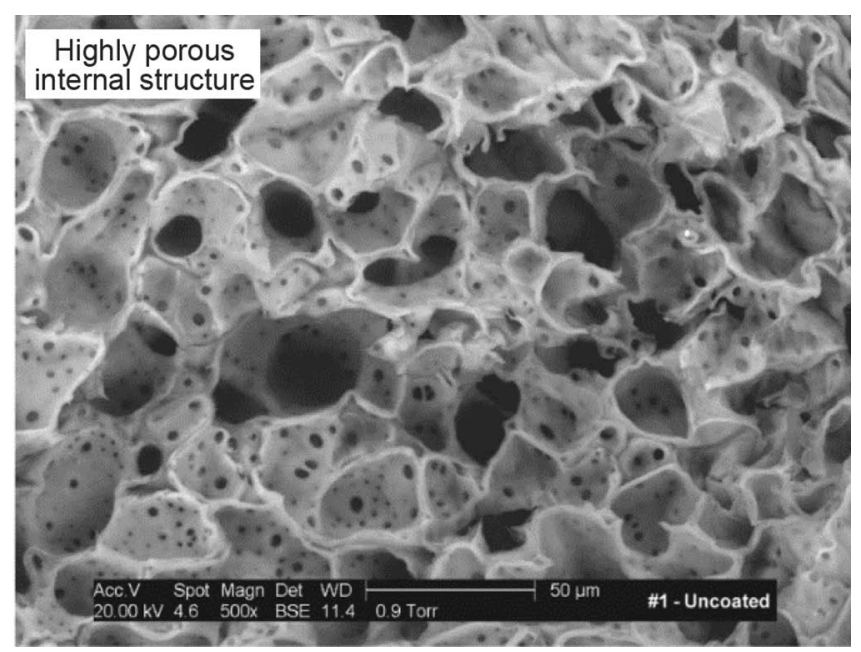

Fig. 4 Photograph showing the angularity of a 1.25 specific gravity ULW proppant (Rickards et al. 2006) 


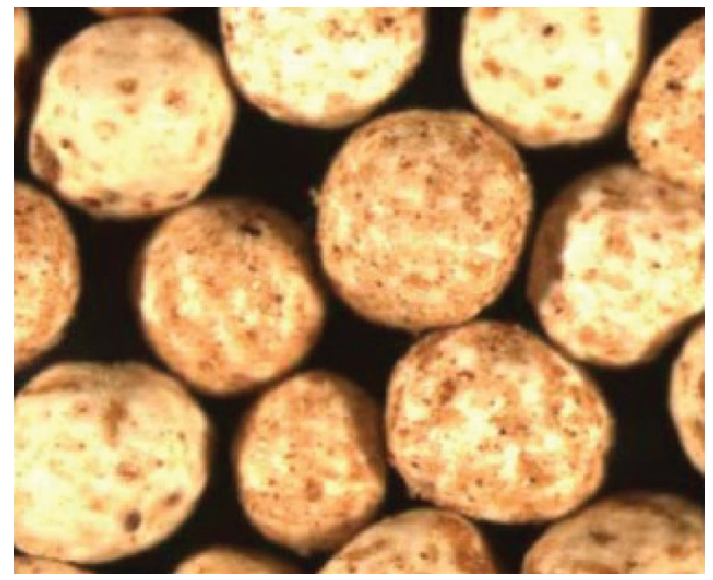

Fig. 5 Picture showing the sphericity of ULW-3 (Jardim Neto et al. 2012b)

and ULW-3 is intermediately rounded. The porosity of packing with ULW-1 is the highest among the three types of proppants. Figure 7 shows particle size distribution of the three proppants. It can be seen that ULW-2 has a wide particle size distribution and a poor uniformity coefficient, and the two other distributions are relatively concentrated.

\subsection{Settling speed of ULW proppants}

The results of different types of proppant settlement experiments are shown in Fig. 8. The proppant type varied, and slick water with a relative density of 1.0 and a viscosity of 1-3 cps was used as the fracturing fluid. The relative viscosity of the fracturing fluid can be set to fixed values. From Fig. 8, the settling speed of 20/40 traditional quartz sand and ceramsite reaches or exceeds $16.5 \mathrm{ft} / \mathrm{min}$. The settling speed of 40/80 mesh coated lightweight ceramic (LWC) proppant is $8 \mathrm{ft} / \mathrm{min}$, whereas the settling speed of 40/100 ULW proppant is $0.08 \mathrm{ft} / \mathrm{min}$. Under the same conditions, the settling speed of the ULW proppant is much lower than those of quartz sand and ceramsite (Brannon and Starks 2009).

\subsection{Strength and conductivity of ULW proppants}

Proppant crushing experiments were conducted at $25^{\circ} \mathrm{C}$ and $95{ }^{\circ} \mathrm{C}$ under the pressure of $103 \mathrm{MPa}$, and the stress was continuously loaded for $2 \mathrm{~min}$. Individual particle strengths were also tested at $90^{\circ} \mathrm{C}$ (Gaurav et al. 2012; Gu et al. 2015). The fine particle content was further analyzed after the test was completed. As shown in Table 3, the experimental results show that ULW-1 and ULW-2 produced only a small number of fine particles, while ULW-3 produced relatively more fine particles. In addition, the single-particle strength test shows that ULW-1 is shaped and easily deformed, and the difference among particles is large; ULW-3 is brittle, and a single particle has the lowest damage point. The strength characteristics of ULW-2 are in between those of ULW-1 and ULW-3.

Figure 9 shows that the conductivity of $0.02 \mathrm{lb} / \mathrm{ft}^{2} \mathrm{ULW}$ 1.05 proppants at 4000 psi closure is 3 times greater than

Table 2 Basic performance (Gaurav et al. 2010; Gu et al. 2015)

\begin{tabular}{llllll}
\hline Proppant & Bulk density, $\mathrm{g} / \mathrm{cm}^{3}$ & Nominal density, $\mathrm{g} / \mathrm{cm}^{3}$ & Sphericity & $\begin{array}{l}\text { Proppant poros- } \\
\text { ity, } \%\end{array}$ & Size \\
\hline ULW-1 & 0.60 & 1.08 & 1 & 44 & Spherical/round \\
ULW-2 & 0.77 & 1.25 & $0.62 \pm 0.7$ & 36 & Angular \\
ULW-3 & 1.19 & 1.75 & $0.78 \pm 0.1$ & 31 & Roughly Rounded \\
\hline
\end{tabular}

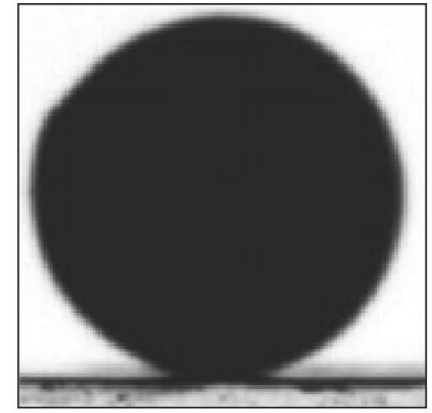

ULW-1

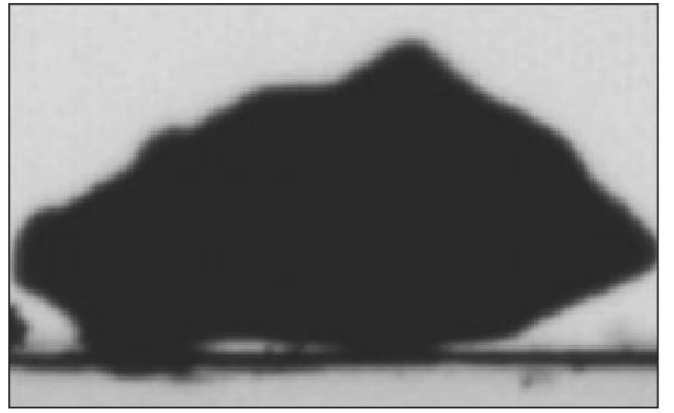

ULW-2

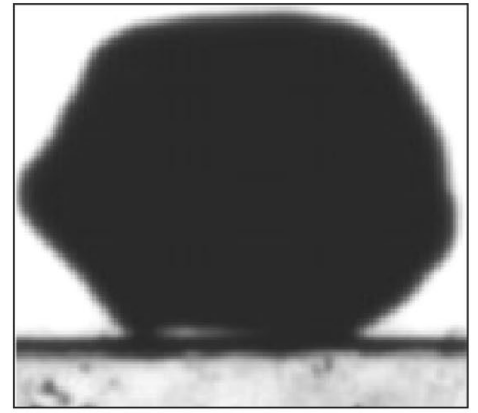

ULW-3

Fig. 6 Two-dimensional close-up images of ULW with a magnification of $23 \times$ (Gaurav et al. 2010) 


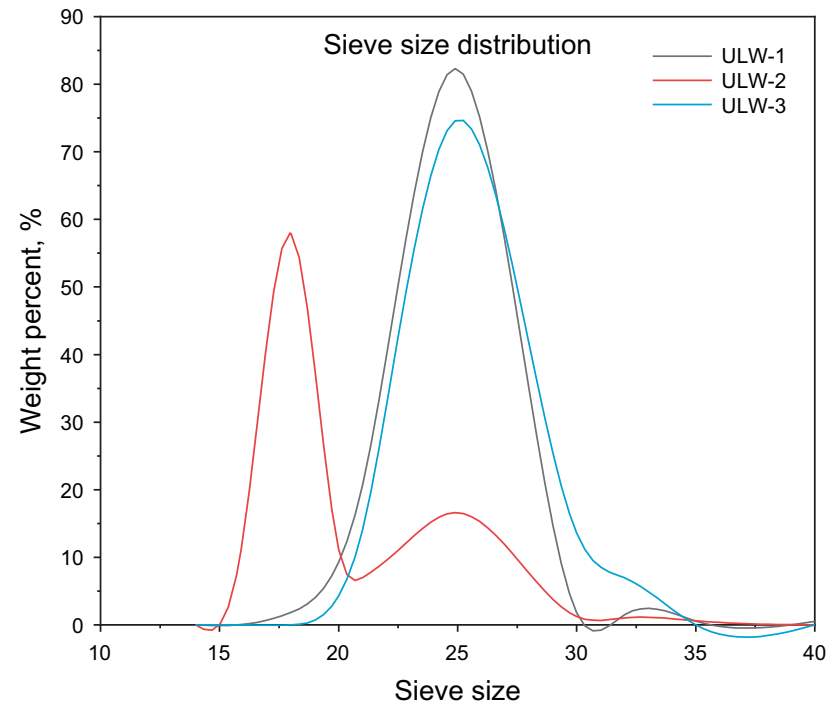

Fig. 7 Sieve size distribution of ULW proppants (Gaurav et al. 2010)

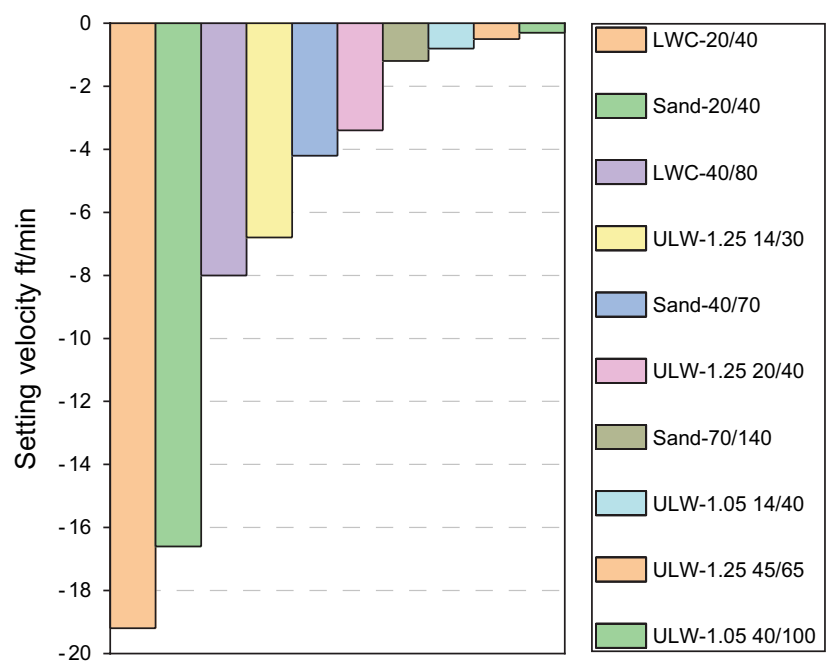

Fig. 8 Settling rate for proppant types and size (Brannon and Starks 2009)

that of $1.0 \mathrm{lb} / \mathrm{ft}^{2}$ pack of sand. However, the three types of proppants have opposite changes in displacement efficiency. Figure 10 illustrates the simulation result of displacement efficiency of different proppants. The sand distribution is highly nonuniform, while ULW proppants approach the upper areas as they move further from the wellbore into the reservoir. Among the ULW proppants, ULW-1 generates a proppant bed with the lowest conductivity, but it exhibits the best proppant placement efficiency, i.e., the largest propped area with a uniform conductivity; ULW-3 builds a proppant bed with the highest conductivity, but the bed length is shorter and smaller than that of ULW-1. In short, the use of ULW proppant can obtain a large effective fracture support area, improve the production degree and conductivity of the reservoir, especially the tight reservoir with serious vertical heterogeneity, and enhance the effect of increasing production.

\subsection{Propped fracture area and increased production effect of ULW proppants}

Compared with the application of conventional proppants, the application of 40/80 mesh ULW proppants combined with slick water provides better proppant transport capacity, conductivity, and borehole performance. Table 4 compares the fracturing effects of conventional and ULW proppants. The simulation results show that the effective fracture area and productivity of fractures in wells with ULW fracturing are significantly higher than those of ordinary proppants. Although the unit price of ULW proppant is high, the ULW technology can achieve full fracture support and high conductivity by using low sand paving concentration. Therefore, the overall cost of fracturing operations has not changed much (Brannon and Starks 2009).

\section{Surface modification technology of ULW}

\subsection{Theory}

The surface of a lotus leaf has a microscopic structure, and this microscopic tower-like structure has a nanoscale wax crystal structure, which transforms its wettability state into a Cassie-Baxter state (Feng et al. 2018). These interactive structures increase the surface area of the lotus leaf but prevent any liquid from interacting with the leaf surface (Guo

Table 3 Percent of fines formed and average value of Young's modulus for proppant packs (Gaurav et al. 2010)

\begin{tabular}{lllll}
\hline Proppant & $\begin{array}{l}\% \text { fine formed @ 103 } \mathrm{MPa}, \\
25^{\circ} \mathrm{C}, \text { wt } \%\end{array}$ & $\begin{array}{l}\% \text { fine formed @ 103 } \mathrm{MPa}, \\
95^{\circ} \mathrm{C}, \text { wt } \%\end{array}$ & $\begin{array}{l}\text { Young's modulus @ 103 MPa, } \\
25^{\circ} \mathrm{C}, \mathrm{MPa}\end{array}$ & $\begin{array}{l}\text { Young's modulus } \\
\text { @ 103 } \mathrm{MPa}, 95{ }^{\circ} \mathrm{C}, \\
\mathrm{MPa}\end{array}$ \\
\hline ULW-1 & $\sim 4$ & $\sim 0.4$ & 172 & 138 \\
ULW-2 & $\sim 2.5$ & $\sim 1.5$ & 172 & 138 \\
ULW-3 & $\sim 14$ & $\sim 30$ & 310 & 310 \\
\hline
\end{tabular}




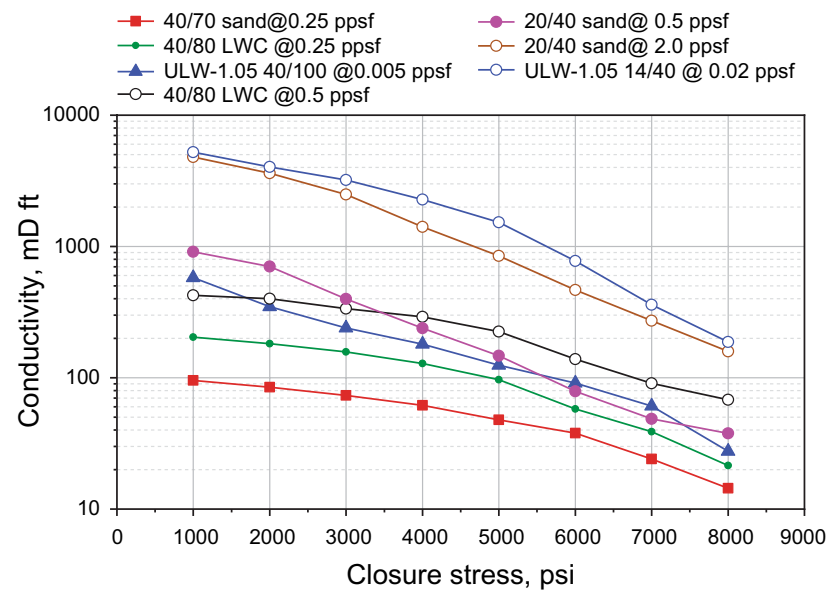

Fig. 9 Proppant conductivity vs. closure stress (Brannon and Starks 2009)

et al. 2011). This characteristic imparts the self-cleaning properties of lotus leaves. The lotus effect mainly refers to the superhydrophobicity and self-cleaning properties of the lotus leaf surface. Given that a lotus leaf has a hydrophobic, nonabsorbent surface, rainwater falling on the leaf surface will form water droplets due to the effect of surface tension (Yamamoto et al. 2015). That is to say, the contact angle between water and the leaf surface will be greater than $150^{\circ}$; when the leaf surface is slightly inclined, the water drops will roll off the leaf surface. The water droplets and impurities of the lotus leaf do not adhere to the surface but roll away, cleaning the surface (Nosonovsky and Bhushan 2009), as shown in Fig. 11. On the basis of the above principles, the researchers modified the proppant surface. Compared with a conventional proppant, the flow resistance required for fluid flow in the pores of the modified proppant is much lower. The modified proppant decreases its liquid adhesion, which causes the fluid to flow into the reservoir from the well (Song et al. 2014).

\subsection{Surface modification technology of common proppants}

To improve the fracturing effect and increase oil production (Bestaoui-Spurr et al. 2017b; Fu et al. 2016; Shrey 2018), surface modification technology is introduced to modify the surface properties of fracturing proppants. The technology can sustain flow channels for oil for a long term after the

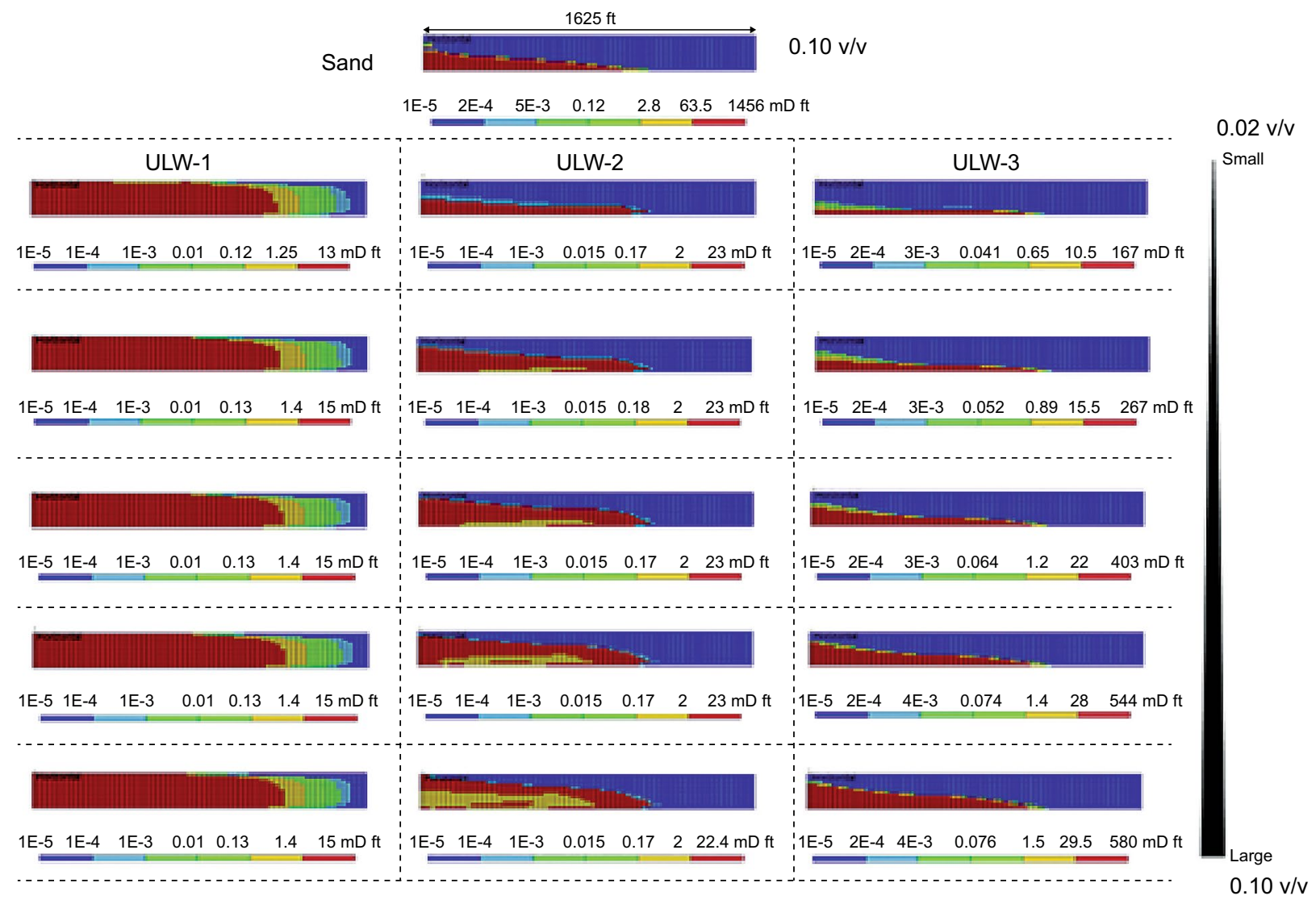

Fig. 10 Conductivity distributions for different proppants in $0.1 \mu \mathrm{D}$ shale (Gu et al. 2015) 
Table 4 Summary of effective fracture area, conductivity, and 360-day cumulative production forecast

\begin{tabular}{|c|c|c|c|c|c|}
\hline No. & Proppant & $\begin{array}{l}\text { Effective FracArea, } \\
\%\end{array}$ & $\begin{array}{l}\text { Cumulative production } \\
\text { ( } 360 \text { days), MSCF }\end{array}$ & Proppant cost, \$ & $\begin{array}{l}\text { Fracturing } \\
\text { treatment } \\
\text { cost, } \$\end{array}$ \\
\hline Frac-1 & Sand, $20 / 40$ & 16.5 & 85,000 & 60,000 & 345,900 \\
\hline Frac-2 & Sand, $40 / 70$ & 23.6 & 131,000 & 90,000 & 401,595 \\
\hline Frac-3 & Sand, $20 / 40$ & 23.7 & 149,000 & 90,000 & 403,230 \\
\hline Frac-4 & LWC, 40/80 & 17.6 & 158,000 & 230,944 & 544,110 \\
\hline Frac-5 & ULW-1.05, 14/40 & 91.5 & 254,000 & 112,728 & 443,883 \\
\hline Frac-6 & ULW-1.05, 40/100 & 96.9 & 188,000 & 57,096 & 350,496 \\
\hline Frac-7 & $\begin{array}{l}\text { Sand, } 40 / 70 \text { and ULW-1.05, } \\
40 / 100\end{array}$ & 89.6 & 176,000 & 111,096 & 494,796 \\
\hline
\end{tabular}

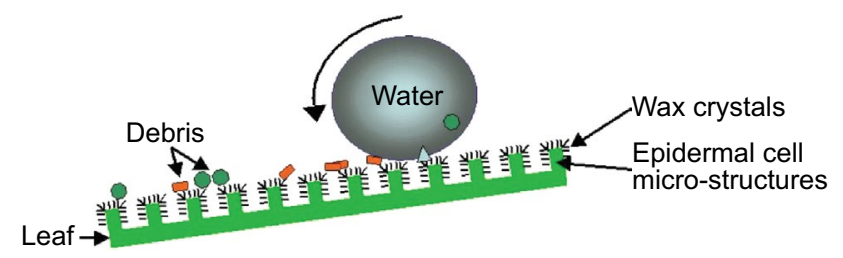

Fig. 11 Illustration of the self-cleaning property of a lotus leaf

hydraulic fracture operation (Fu et al. 2016). The surface modification technology mentioned in this paper is the act of modifying the surface wettability of a proppant from hydrophilic to hydrophobic and oil-wet properties (Shrey 2018; Wang et al. 2016). The technology can change the silt adoption properties of the proppant to prevent plugging (Fu et al. 2016). That is, the special technology can improve the self-cleaning property of the proppant to prevent several blockages, such as slit, scale, asphalt, and corrosion products trapping at flow channels for hydrocarbon (Fu et al. 2016). Figure 12 shows that as the wetting angle increases, the oil productivity index increases. Tabatabaei et al. modified the wettability of proppants by using graphite nanoplatelets (GNPs) (Tabatabaei et al. 2020). The study found that a GNP-coated proppant can increase the cumulative production by approximately $3 \%$ for water-wet formation and $2 \%$ for oil-wet formation after 3-year production. Hence, the GNP-coated proppant is more suitable for water-wet reservoirs. Shrey also obtained similar experimental results (Shrey 2018).

The available literature (Wang et al. 2016) has shown that a hydrophobically modified proppant has high conductivity and closing pressure. For example, at closed stress of $27.5 \mathrm{MPa}$, a hydrophobically modified proppant has a permeability of $20.9 \mathrm{D}$, which is 4 times that of an untreated one, and $20 \%$ improvement in conductivity compared with the untreated one. CARBO has developed an RPM neutral wetting treatment that increases the hydrophobicity and lipophilicity of the proppant surface (Fig. 13), which helps prevent water and water-based fracturing fluids from remaining in the proppant stacking gap, reducing the diversion capacity. In the later stages of mining, this proppant can also control the amount of water produced and increase the amount of oil produced. Figure 14 shows the effect of modifying a proppant before and after using the RPM technology.

Several researchers have developed a neutral-wettability proppant to prevent the adsorption of organic scale, inorganic scale, and other substances on the proppant surface and then block the oil flow channel. For example, Baker Hughes developed a neutral-wettability proppant that eliminates the pressure drop in multiphase flow and reduces fluid residue attachment (Bestaoui-Spurr and Hudson 2017). As a result, the fluid has a high flow capacity in the proppant pores over a long period of time (Fig. 14).

\subsection{Surface modification technology for ULW proppants}

The main causes of loss of permeability in a proppant pack are proppant flowback, fines, and gel damage (Valko and Economides 1997). A permanently modifying technology of the proppant surface can help improve the proppant pack conductivity and accelerate well cleanup (Valko and Economides 1997). One method is to decrease proppant flowback and polymer damage inside the pack by using a resin-coating technology on proppant surfaces (Bestaoui-Spurr et al. 2017b). Another method is using superhydrophobic chemicals to treat proppant surfaces directly (Bestaoui-Spurr et al. 2017a; Shrey et al. 2018). These additives can limit the mobilizing of fines (Weaver and Nguyen 2010). Permanent surface modification can also alter the original wettability on the proppant surface into neutral wettability, thereby decreasing the intermolecular forces between the surface and fluid and leading to easy fluid flow. That is, the capillary pressure is null for water- and hydrocarbon-based fluids, keeping the pores wide open for flow (https://www.aogr.com). From 


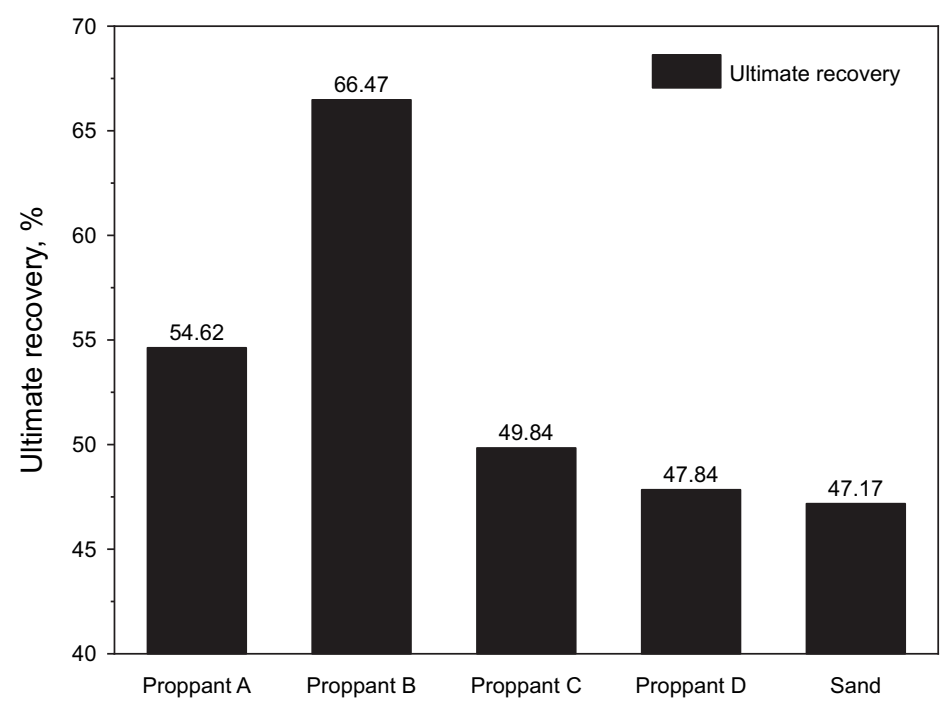

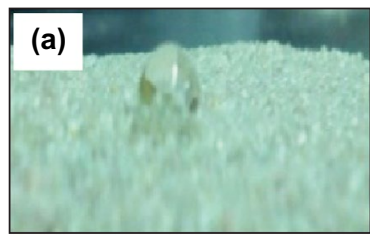
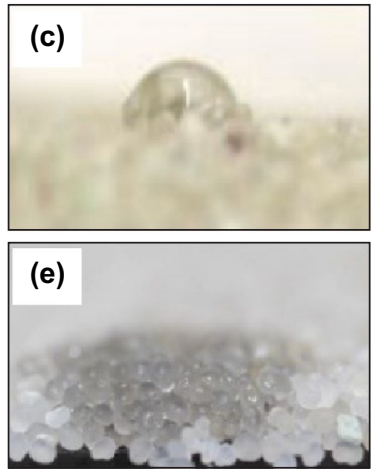

(b)

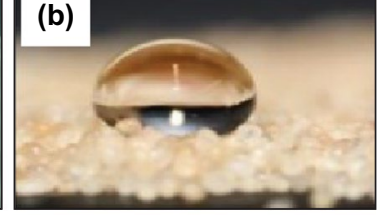

(d)

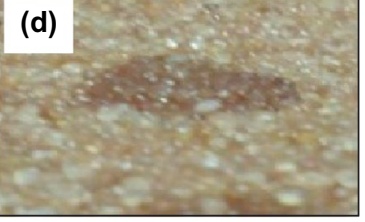

Fig. 12 Ultimate recoveries of various proppant types (Parmar 2013)
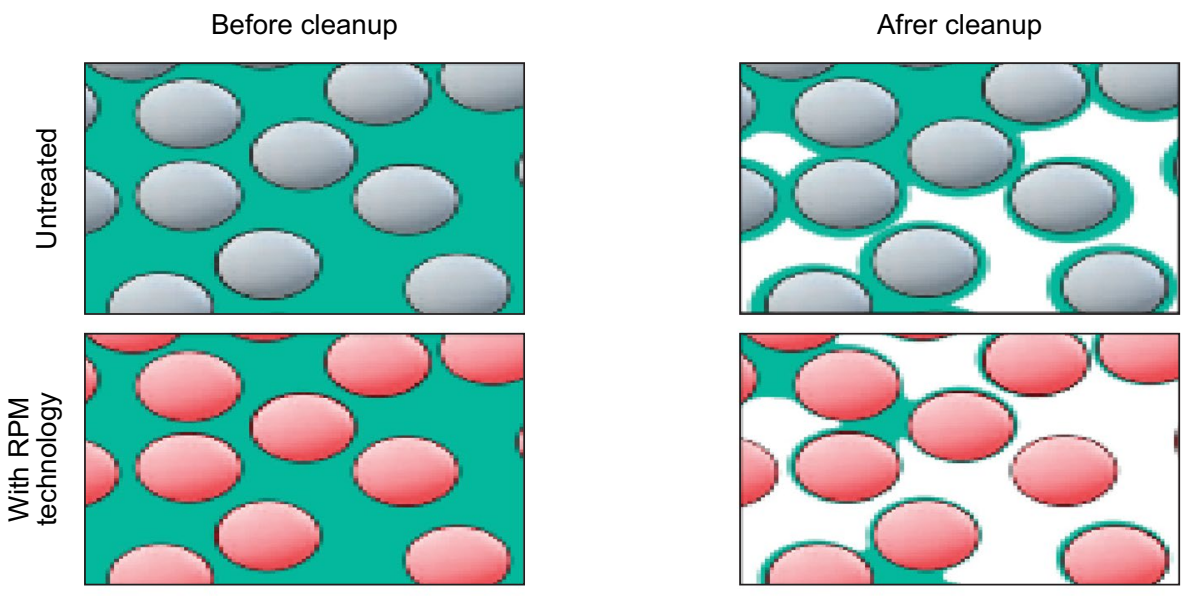

Single phase flow
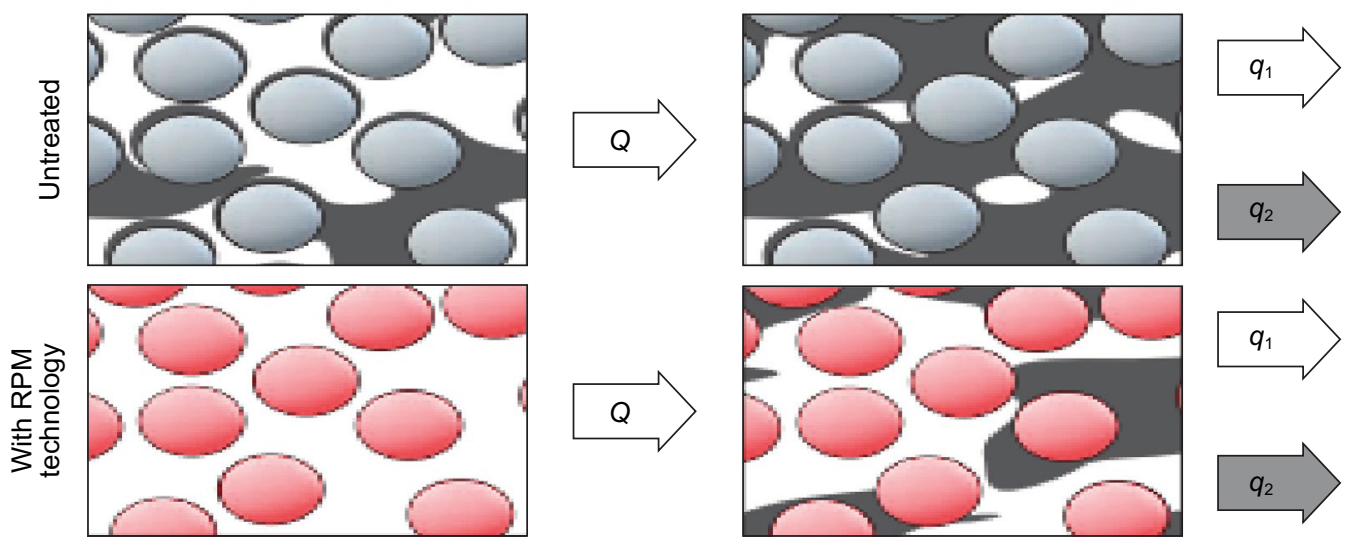

Fig. 13 Increased fracture fluid cleanup, fracture length, and conductivity; reduced multiphase flow pressure drop by using RPM technology (http://www.carboceramics.coin/) 


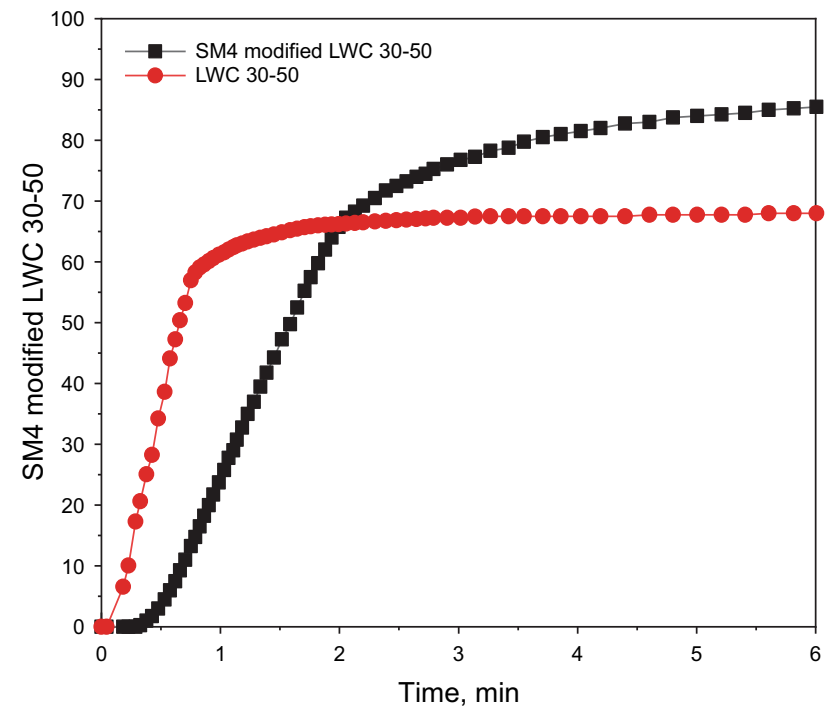

Fig. 14 Column test of an SM4 surface-modified lightweight ceramic proppant $(30 / 50$ mesh) compared with a control untreated light ceramic proppant (30/50 mesh) by using water as flowing fluid (Bestaoui-Spurr and Hudson 2017)

Fig. 15, conventional proppants limit the oil flow through the proppant pores, whereas the ULW with NeutraProp ${ }^{\mathrm{TM}}$ treatment allows the fluid to flow freely through the proppant pores. In addition, the modified proppant has evident oil-increasing and water-blocking effects and can help improve the proppant crushing resistance to a certain extent (Fig. 16).

In 2015, Han proposed a new type of miscellaneous and coated polymer ULW proppant (Han 2015). He used styrene as a monomer, benzoic acid benzoate (BPO) as an initiator, diethyl benzene (DVB) as a cross-linker, and an inorganic filler as a modifier. Graphite-modified polystyrene microspheres were coated with epoxy/saturated acid resin to improve the comprehensive performance of the proppant. The experimental results showed that the modified polymer microsphere proppant declined the flow resistance of oil compared with the traditional proppant.

In 2016, Liang used the hydrophobic properties of pine bark to polymerize pine bark and polystyrene to form a superabsorbent ULW proppant with a surface wetting angle of $120^{\circ} \mathrm{C}$ (Fig. 17) (Liang et al. 2016).

\section{Field applications of ULW proppants}

\subsection{Several commercial ULW proppants}

Three ULW proppant technologies are currently popular. One is KRYPTOAIR proppant produced by CARBO. The technology is characterized by precision-engineered, strong, durable, round, single-mesh-size, and smooth proppant grains. The advantages of the KRYPTOAIR proppant are the excellent transport characteristics in a complex fracture

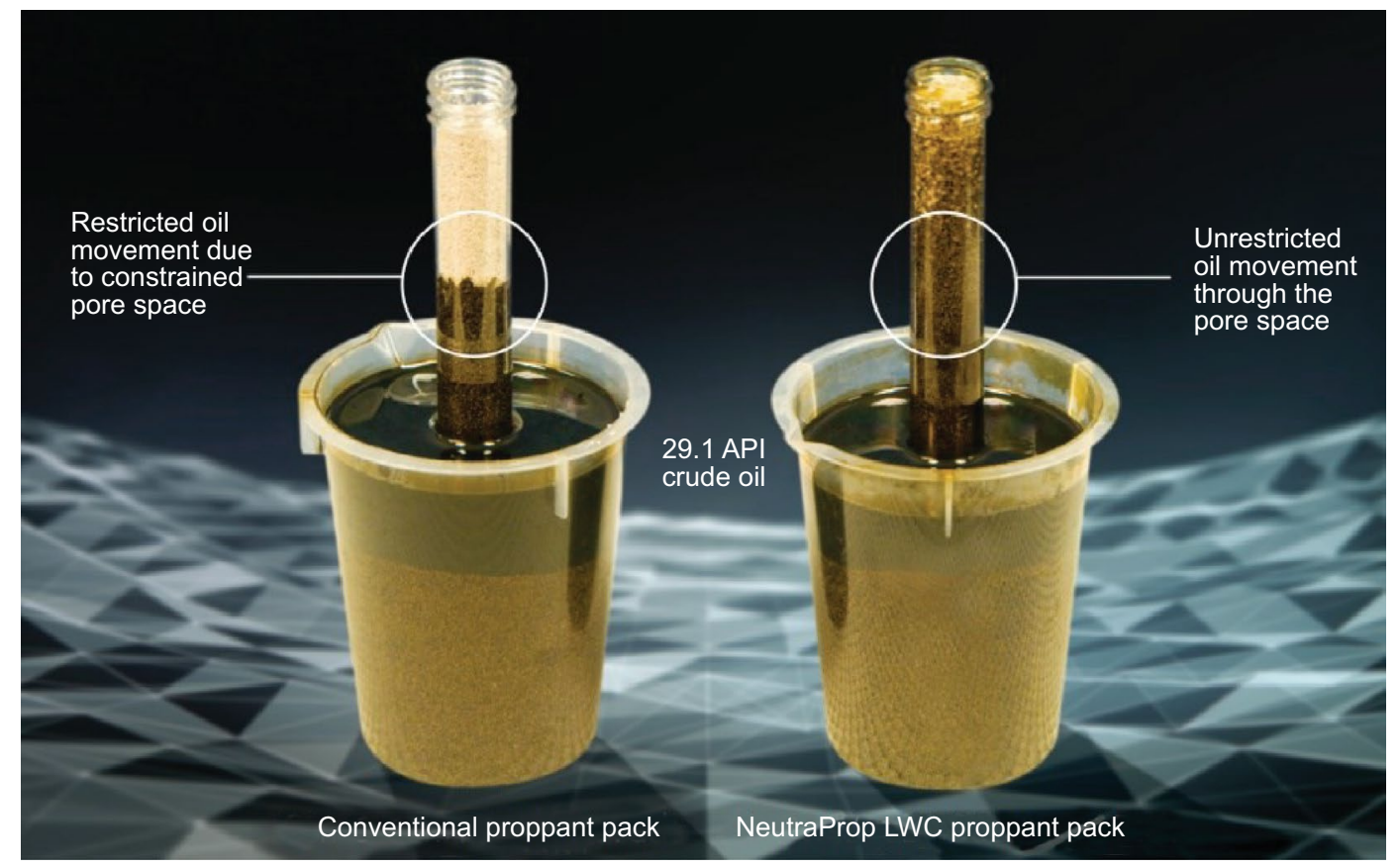

Fig. 15 Laboratory test demonstrating how a conventional, untreated proppant can trap fluids in particle pore spaces, whereas the NeutraProp LWC surface-modified proppant allows fluids to flow freely through the proppant pack (https://www.bakerhughes.com) 

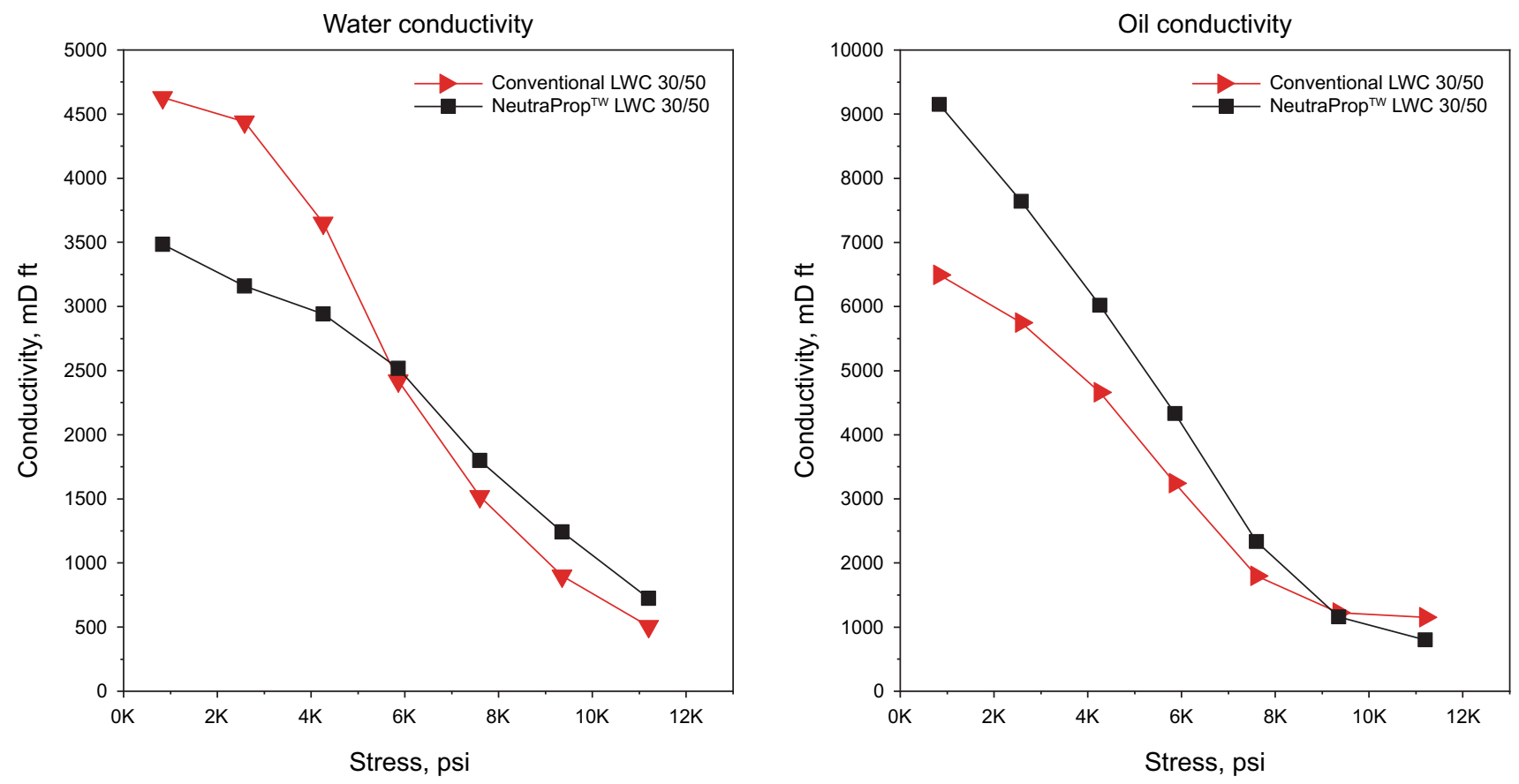

Fig. 16 Typical conductivity to water (left) and oil (right) for NeutraProp LWC compared with the control at $250{ }^{\circ} \mathrm{F}$ and for a loading of $2 \mathrm{lb} /$ sqft (https://www.bakerhughes.com)

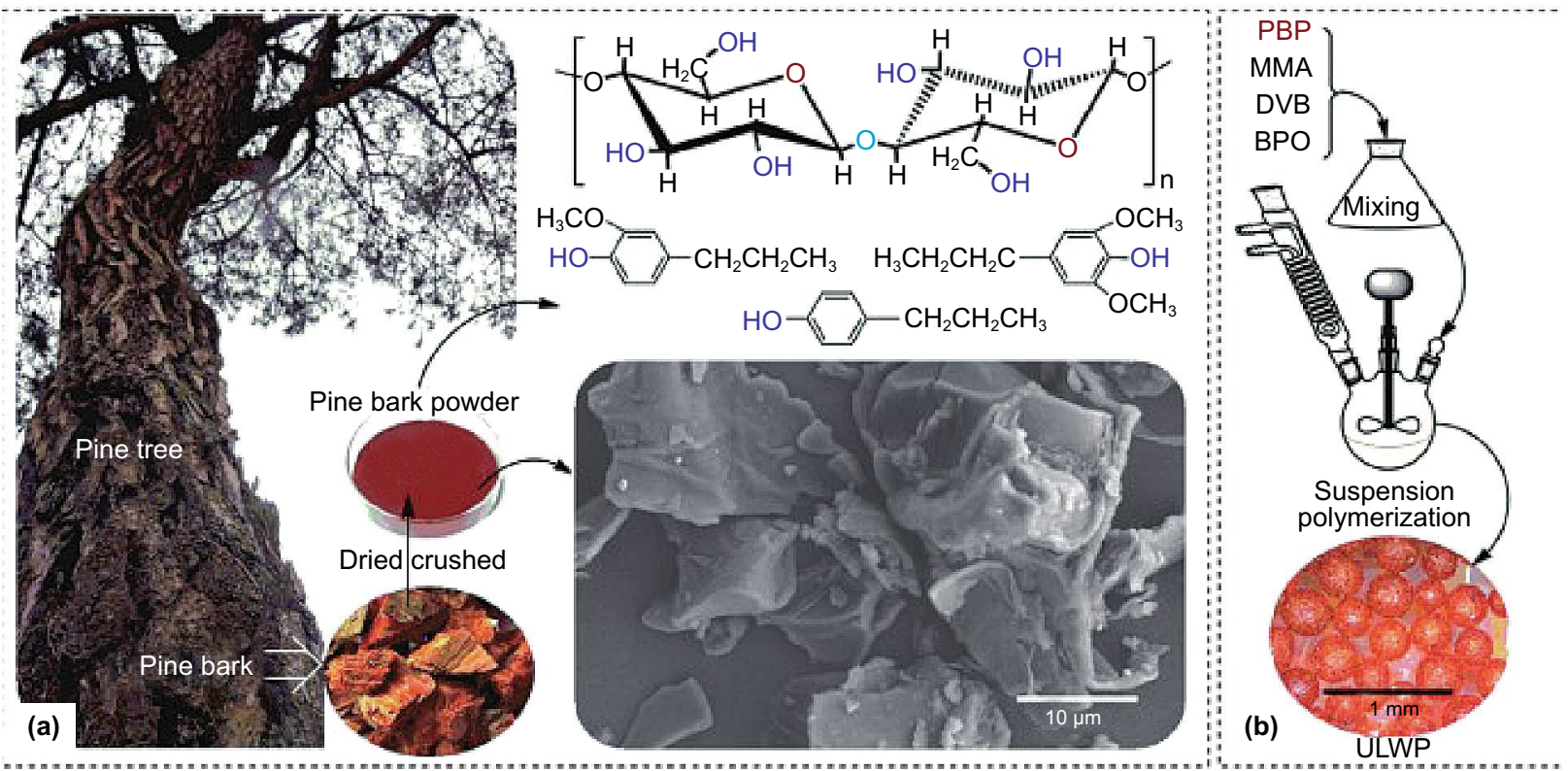

Fig. 17 Collection of pine bark and preparation of proppant (Liang et al. 2016)

network and the high efficiency of packing within annular space between sand control screen and formation. It can also be used with slickwater, which avoids the damage of reservoirs and environmental pollution resulting from gel (https ://www.carbodirect.com). Another is LiteProp ${ }^{\mathrm{TM}}$ Prime 108 proppant produced by Baker Hughes. The transport of
LiteProp Prime108 proppant in fracture fluid is extremely efficient, and inherently slow settling rates provide an optimal fracture height. In addition, LiteProp Prime 108 proppant improves logistics and economics by producing a greater equivalent effective fracture with fewer pounds of proppant than that required with sand. When used in 
horizontal open-hole gravel packing operations, LiteProp Prime 108 proppant shows a great advantage in filling efficiency. Table 5 summarizes the performance of several other ULW proppants produced by Baker Hughes (https://www. bakerhughes.com). The other is a self-suspending polymer proppant produced by Beijing Qixiangda New Material Co., Ltd in China. The density of the proppant is close to that of slickwater, which can effectively avoid the settlement of proppant in fractures and damage to the formation. The main advantages of the proppant are summarized in the following (http://www.qisintal.com).

1. It owns better chemical inertness than ceramsite. So, formation conditions and fracturing measures have the least influence on proppant performance;

2. It has a good self-cleaning function and surface smoothness, avoiding mineral deposits in the formation or adhesion of organic colloids and fracturing fluid in the formation to the proppant;

3. The surface wettability of the proppant has been modified, which obtains the function of increasing oil and prevent water;

4. It can be carried by slickwater, effectively reducing pumping power and eliminating or reducing restrictions on design parameters;

5. It can be used for clean water fracturing, but the formation temperature does not exceed $145^{\circ} \mathrm{C}$.

Table 6 shows the basic parameters of the special proppant. In addition, the ULW proppants produced by other companies have also been applied in oilfield, such as SUN -LUBRAMAX ${ }^{\mathrm{TM}}$ services company, BJ services company and Daqing Yongchen Petroleum Technology Co., Ltd in China.

\subsection{Application in gravel packing operations}

Gravel packing of horizontal wells usually requires the use of traditional ceramsite proppant or natural gravel and viscous pumping fluid, such as viscosified linear gel, crosslinked gel fluids, or Newtonian fluids (Chen 2012). However, as the length of horizontal well sections continues to increase, the use of traditional fluids and gravel to complete gravel packing operations will become difficult or uneconomical for some special formations, such as formations with low-pressure gradients, formations with severe leakage, or formations with rat holes that require low pump flow rates or low pump pressures (Martins et al. 2009). Meanwhile, a low displacing rate can easily lead to a large amount of settlement and even the formation of sand bridging in the annulus, resulting in insufficient filling of the bridge plugs to the casing shoes. This condition can cause sand control failure. Therefore, a limited pump speed window exists, as shown in Fig. 18 (Jardim Neto et al. 2012a).

In the field, reducing the pump speed is the most practical and effective method. However, reducing the pump speed will also reduce the proppant delivery speed, which will dangerously increase the risk of premature screen-out at the end of the rat hole and the dune height (Jardim Neto et al. 2012a). One way to solve the above problem is to provide an alternative path for the slurry by detouring the bridge

Table 5 Comparison of several ULW proppants

\begin{tabular}{|c|c|c|c|c|}
\hline Commercial ULW proppants & LiteProp Prime 108 & LiteProp 125 & LiteProp 140 & LiteProp 175 \\
\hline Specific gravity, $\mathrm{g} / \mathrm{cm}^{3}$ & 1.06 & 1.25 & 1.39 & 2.0 \\
\hline Bulk density, lbs/ $/ \mathrm{ft}^{3}$ & 40.4 & 52 & 54.3 & 73.5 \\
\hline Neutral buoyancy brine, ppg & 8.84 & 10.4 & 11.66 & 15.85 \\
\hline Maximum BHST, ${ }^{\circ} \mathrm{F}$ & 275 & 275 & 275 & 275 \\
\hline Sphericity/roundness & $0.9 / 0.9$ & Both $>0.6$ & $0.90 / 0.84$ & Both $>0.8$ \\
\hline Acid solubility, $\%$ & 0.3 & 0.1 & 0.1 & 4.3 \\
\hline Mesh size & $14 / 40$ & $14 / 30,20 / 40$ & $\begin{array}{l}\text { 16/30, 20/40, other } \\
\text { sizes, upon request }\end{array}$ & $20 / 40$ \\
\hline $\begin{array}{l}\text { Permeability at } 1000 \text { psi clo- } \\
\text { sure stress, D }\end{array}$ & 212 (14/40 mesh) & $234(20 / 40)$ & $250(16 / 30$ mesh $)$ & 170 (20/40 mesh) \\
\hline Appearance & & & PSES & \\
\hline
\end{tabular}




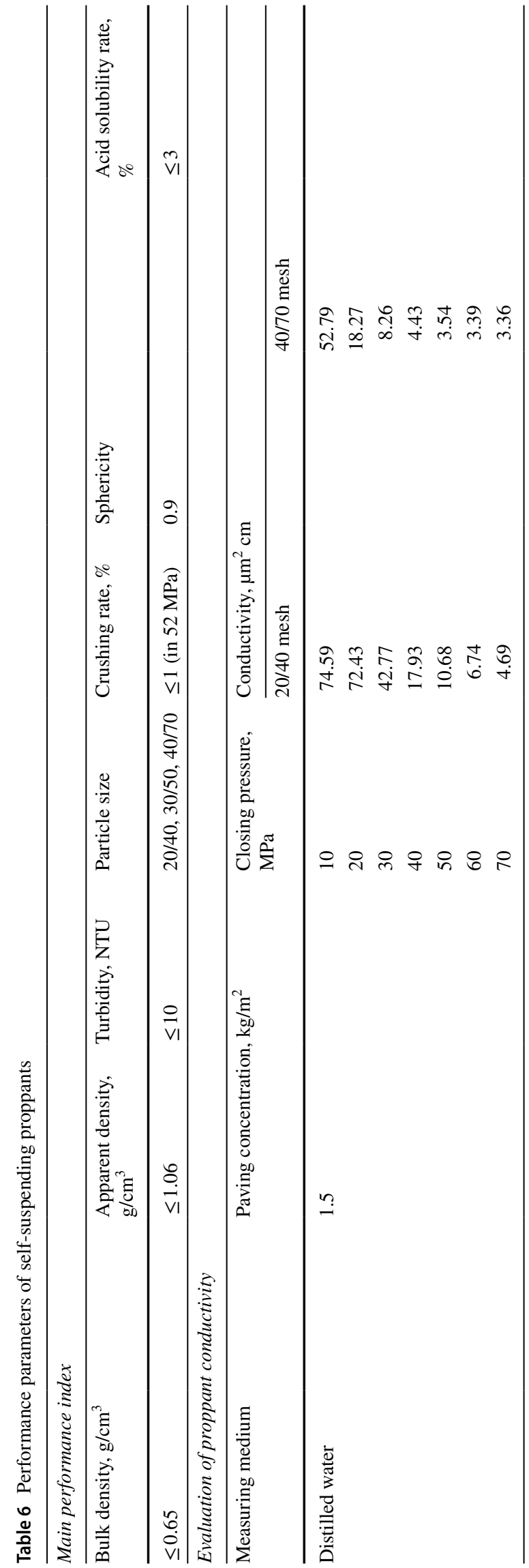

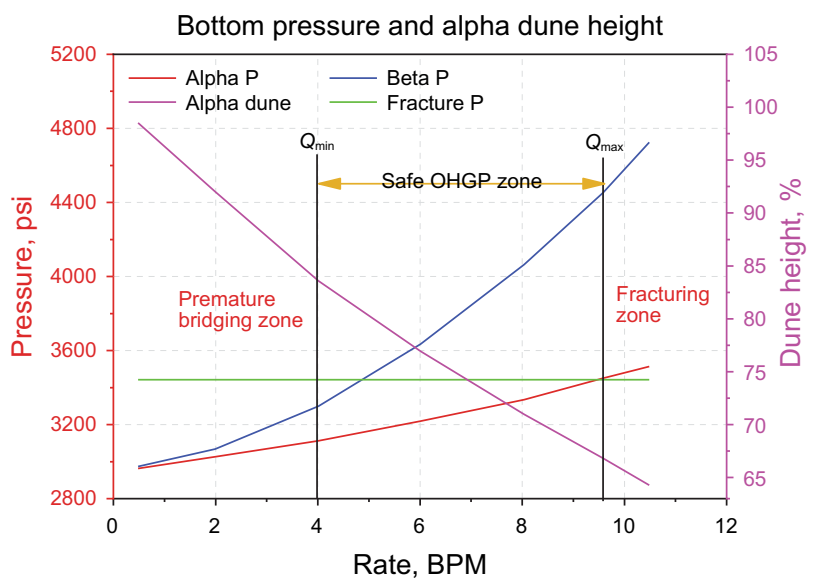

Fig. 18 Operation pumping window for horizontal open-hole gravel packs (Jardim Neto et al. 2012a)

plugging formed in the previous (Ojo 2004). However, this solution increases the completion cost. Another method is the introduction of ULW. This method can significantly reduce the pump rate to avoid fracturing the formation with low-pressure gradients. No risk of the premature settlement of proppant and formation of sand dunes will occur, which can make the filling rate reach $100 \%$ (Trujillo et al. 2011).

From 2005 to 2011, 12 wells were packed with ULW1.25 proppant in offshore Brazil. Compared with traditional proppants, ULW proppants have a lower pump displacement. Given that the pressure drop is proportional to the square of the pump flow, reducing the pump flow can significantly reduce the pressure drop. The possibility of pumping ULW1.25 at low rates increases the length of the fillable horizontal section and allows filling in low-fracture-gradient wells, eliminating the need for expensive mechanical equipment (Jardim Neto et al. 2012a). Meanwhile, the technology can effectively reduce the dune height (Fig. 19).

Table 7 indicates that the static settling rate of ULW-1.25 particles is $75 \%$ lower than that of conventional ceramics and $62 \%$ lower than that of ULW-1.75 particles. During the beta wave, pumping ULW-1.25 can greatly reduce the sedimentation velocity and allow a decreased proppant transmission speed, and no blockage of the circulation path will exist in the narrow passage (Trujillo et al. 2010). A case history comparison between two wells was reported in SPE 96818 (Chambers and Meise 2005). The data indicate that the fractured well with ULW-2 had 100\% more surface area exposed and over 6 times conductivity compared with the well fractured using a conventional proppant. As of 2004, ULWP-2 has been applied for thousands of wells. Compared with ULW-1.25 (Bestaoui-Spurr and Hudson 2017), ULW-3 has better sphericity and surface roughness. In 2007, a Brazilian oil field used ULW-3 instead of ULW-2 for gravel pack sand control completion and achieved good results. So, the 


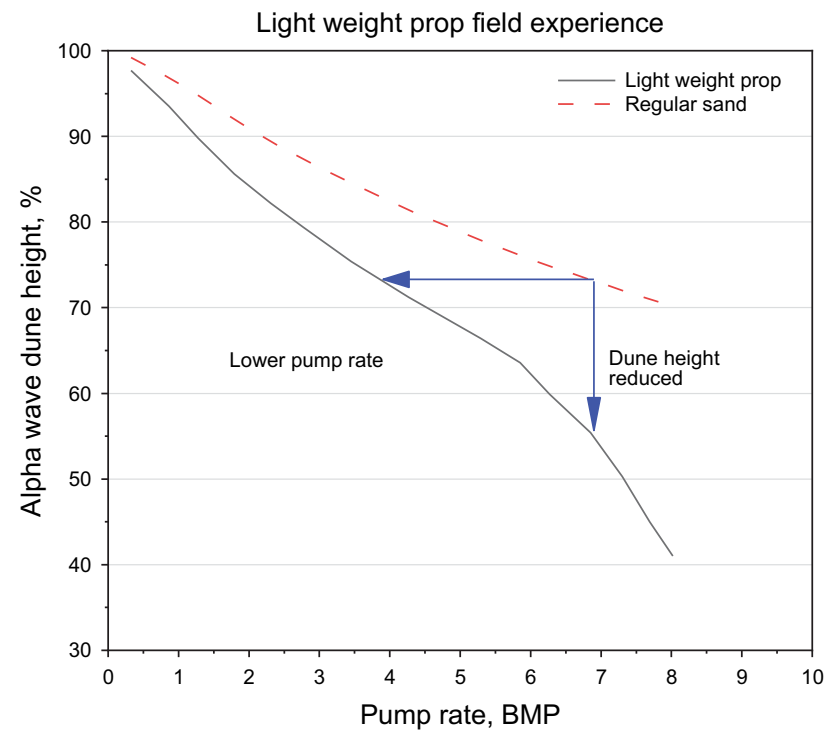

Fig. 19 Lightweight and ultralightweight proppant field job experiences (Chen 2012)

Table 7 Comparison of different gravel settlement speeds

\begin{tabular}{lll}
\hline 20/40 proppant & Specific gravity, $\mathrm{g} / \mathrm{cm}^{3}$ & $\begin{array}{l}\text { Settling } \\
\text { velocity, ft/ } \\
\text { min }\end{array}$ \\
\hline Bauxite & 3.65 & 23.2 \\
ISP & 3.15 & 20.0 \\
Carbolite & 2.71 & 17.2 \\
Ottawa sand & 2.65 & 16.6 \\
RCS & 2.55 & 15.9 \\
ULW-1.75 & 1.75 & 11.2 \\
ULW-1.25 & 1.25 & 4.3 \\
\hline
\end{tabular}

use of such ULW proppant effectively solves the problems of rapid settlement of the conventional proppant, and poor filling effect, especially for long horizontal wells or largedisplacement wells (Jardim Neto et al. 2012b).

\subsection{Application in hydraulic fracturing operations}

From statistics, 500 wells in the United States have been treated with ULW from American BJ and Baker Hughes. The cumulative production of wells treated with ULW in Marcellus and the Woodford Basin outperformed the offsets (Fig. 20) (Han et al. 2016). In Fig. 20, the blue bars represent the ULW proppant-treated wells, and the red bars are the offset wells. The production by using ULW treatment is remarkably higher than that with a common proppant.

Around 2003, ULW was widely employed in different oil fields. The following are several specific application examples.

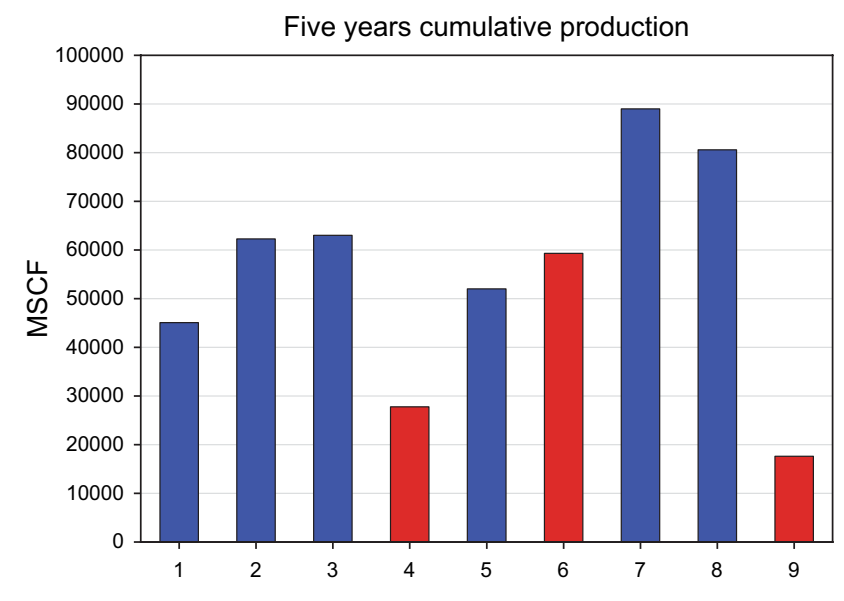

Fig. 20 Comparison of 12-month cumulative production (Han et al. 2016)

1. In the summer of 2003, sand and ULW proppants alone were used to fracture three wells in sandstone in the Arabia oil field in Lawrence County, Ohio. Approximately 270 days of production data from these wells in the Appalachian Basin verified the ability of ULW proppants to maintain fracture conductivity for a long time under reservoir conditions. The data show that the 8 -month cumulative production was $78 \%$ higher than the average level of the selected area (Myers et al. 2004).

2. In southwestern Pennsylvania, approximately 3,000 lb of 20/40 mesh ULW and 16,500 lb of 20/40 mesh sand were used in multiple fracturing stimulation operations. Among eight ULW wells, the monthly average production of five wells exceeded the peak, and several wells were $50 \%$ or more above the average (Myers et al. 2004).

3. In areas of the Big Sandy Field, ULW proppants were used in large-scale foam fracturing operations. The data provided indicated that among the five wells using ULW proppants, the stimulation effect of four wells was comparable to that of conventional proppants and even exceeded their stimulation effect (Kendrick et al. 2005).

4. The Granite Wash in Hemphill County, Texas is a deep, low-permeability zone, where proppant areal coverage is extremely important to well productivity. Generally, viscous fluids are used to carry proppants and have the function of partially supporting fractures, but residues in the viscous fluids can damage the reservoir or reduce the filling rate of proppants. High production pressure differentials are required when clean fluids are used for cleaning operations. Nonetheless, the use of ULW-1.25, from BJ Services Company, greatly reduces the requirements for fluid viscosity. Then, the permeability of the reservoir can easily be restored after the operation (Rickards et al. 2006). As demonstrated in Fig. 21, the gas 

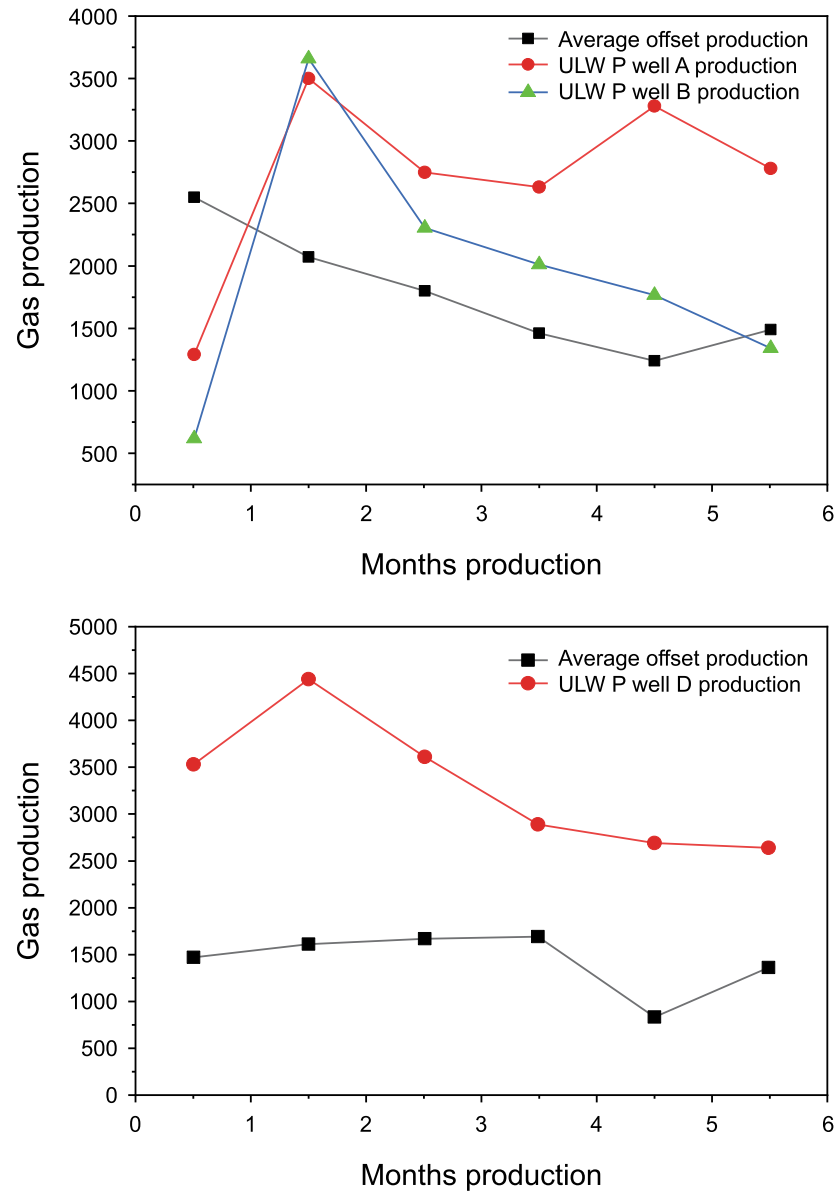

Fig. 21 ULW proppant well vs. offsets (Kendrick et al. 2005)

productivity of wells treated with ULW is better than that of wells treated with an ordinary proppant.

In 2008, the UHQ foam/ULW-1 proppant was first used in the Huron Shale Well in the Big Sandy Field for hydraulic fracturing. Compared with wells that underwent conventional fracturing, the UHQ foam/ULW-1 treated wells increased the cumulative production by $46 \%$ after 210 days (Parker et al. 2012). With the development of proppant technology, a large number of ULW proppants have been used in the field with remarkable results. A ULW proppant test was performed in Well of 48-6 in Jilin Oilfield in China. The average daily oil production was $4.7 \mathrm{~m}^{3}$ after 2 months, and the output was significantly higher than that of adjacent wells constructed with conventional proppants. Meanwhile, the proppant was also used in Daqing Oil Field in China. The field test shows that the increase in oil well production has reached $2.1 \mathrm{t}$, which was 0.47 $\mathrm{t} / \mathrm{m}$ higher than the average oil production intensity of the same block. So, the yield increase effect was very evident (Li 2013) (Table 8).
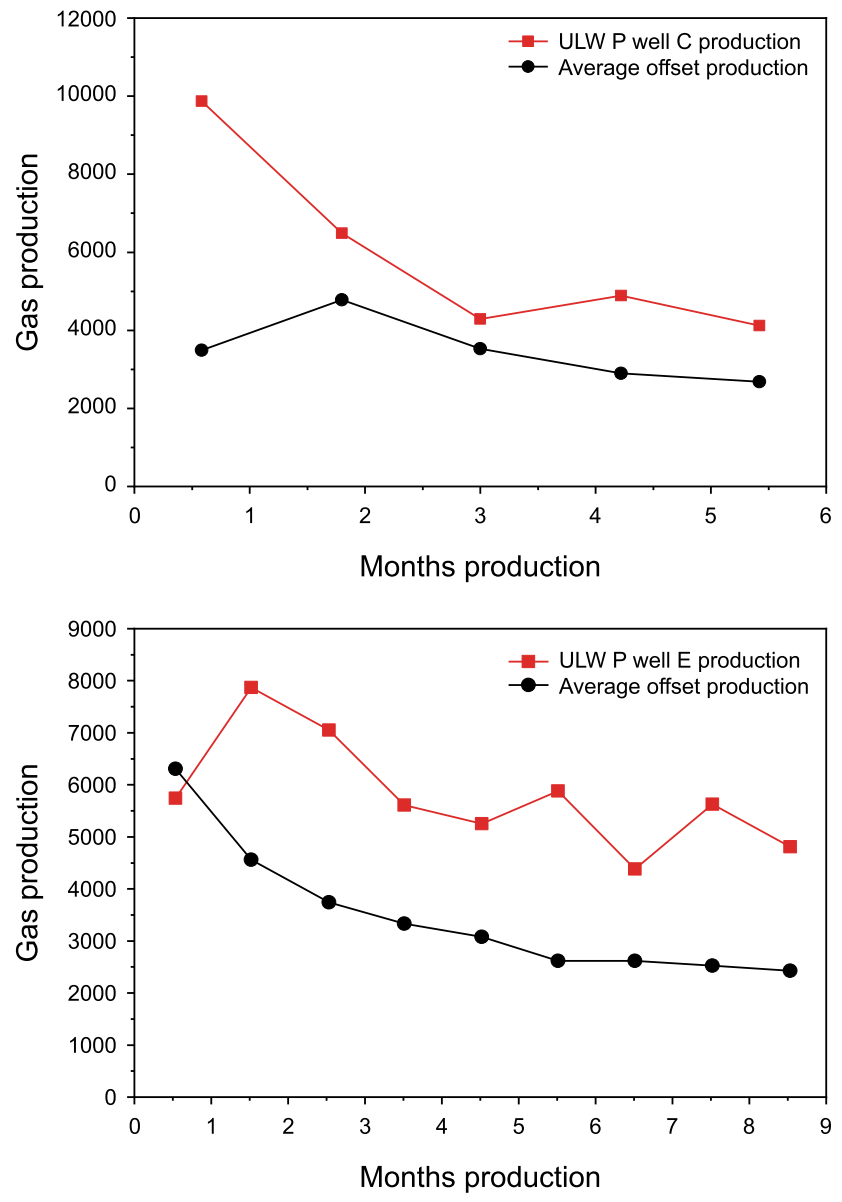

\subsection{Application in water control and oil increase operations}

Baker Hughes recommended the NeutraProp ${ }^{\mathrm{TM}}$ lightweight ceramic neutral-wettability proppant. The product has been successfully used in the Gulf of Mexico and achieved good economic benefits in the industry. Compared with previous wells where a conventional proppant was used, the NeutraProp LWC neutral-wettability proppant saved $\$ 438,000$ USD in flowback cost, eliminated $43 \%$ of rig time, and expedited first-oil production (Fig. 22). For gravel pack sand control or prefilled gravel sand control, this neutral-wettability proppant prevents polar particles, such as clay, from adsorbing onto the proppant surface to block the oil flow passage and reduce the yield (https://www.bakerhughes.com). 
Table 8 Fracturing productivity

\begin{tabular}{llllcc}
\hline Well & Time & $\begin{array}{l}\text { Daily fluid production } \\
\text { rate, } \mathrm{t}\end{array}$ & $\begin{array}{l}\text { Daily oil production } \\
\text { rate, } \mathrm{t}\end{array}$ & $\begin{array}{c}\text { Moisture content, \% } \\
\text { Oil production } \\
\text { index, } \mathrm{t} \mathrm{m}^{-1}\end{array}$ \\
\hline A & Before fracture & 22.4 & 1.9 & 100.0 & 0.39 \\
& After fracture & 20.0 & 4.0 & 80.0 & 0.83 \\
B & Before fracture & 16.1 & 2.4 & 85.3 & 0.46 \\
& After fracture & 15.2 & 4.6 & 69.7 & 0.88 \\
Average & Before fracture & 19.3 & 2.2 & 88.8 & 0.43 \\
& After fracture & 17.6 & 4.3 & 75.6 & 0.86 \\
\hline
\end{tabular}

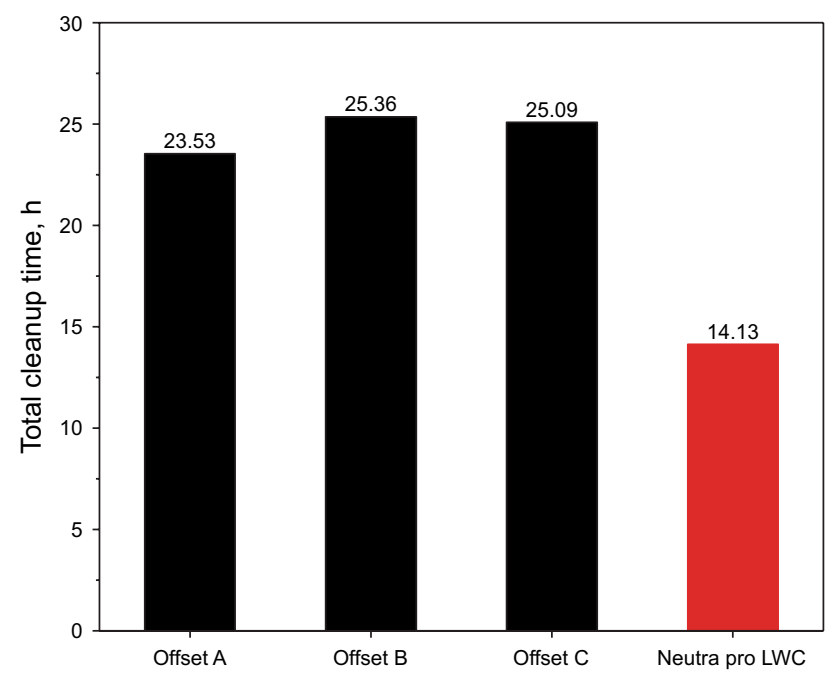

Fig. 22 Comparison of total cleanup time (https://www.aogr.com)

\section{Discussion and conclusions}

On the basis of the preceding analysis, ULW proppants can significantly improve the fracturing effect in tight shale reservoirs and the gravel filling efficiency in deep and ultradeep water or long and ultralong horizontal wells, thus saving operating time and cost. With the development of deeper reservoirs and the more complicated geological conditions, a gap currently exists in proppant technology. In future, additional raw materials should be explored for wells with more complex reservoir conditions to benefit from ULW proppants. The advantages of ULW proppants mainly include the following:

1. ULW proppants are easy to transport, which is conducive to the realization of the full support of longitudinal fractures at a relatively low sand concentration. The technology is especially suitable for large-scale fracturing reformation of tight oil and gas reservoirs to increase the production of fractured wells.
2. Given that the density of ULW proppants is close to that of water, the fracturing fluid is easy to prepare, and less expensive guar gum need not be added. In the fracturing process, a nonviscous fracturing fluid, such as slickwater, can be used, which reduces the cost of fracturing fluid to a certain extent. Slick water facilitates flowback, thereby reducing damage to reservoirs and environmental pollution. After fracturing, flowback or less flowback is not needed, which simplifies the construction process and reduces the labor intensity of the operator. Meanwhile, these features avoid polluting the ground and the environment.

3. In gravel pack sand control operations, ULW proppant technology cannot only significantly increase the packing efficiency but can also effectively reduce the displacement rate. This technology can effectively solve the problems of gravel packing and sand control in special places, particularly ultralong horizontal wells, formations with low-pressure gradients, and formations with substantial leakage.

4. Hydrophobically modified proppants can reduce the oil flow resistance, which helps increase the yield. They can also decrease well cleanup time and improve conductivity.

Acknowledgements The study was supported by Science Foundation of China University of Petroleum, Beijing (No. 2462019YJRC008) and National Natural Science Foundation of China (No. 52074312).

\section{Compliance with ethical standards}

Conflict of interest The authors declare that we do not have any commercial or associative interest that represents a conflict of interest in connection with the work submitted.

Open Access This article is licensed under a Creative Commons Attribution 4.0 International License, which permits use, sharing, adaptation, distribution and reproduction in any medium or format, as long as you give appropriate credit to the original author(s) and the source, provide a link to the Creative Commons licence, and indicate if changes were made. The images or other third party material in this article are included in the article's Creative Commons licence, unless indicated 
otherwise in a credit line to the material. If material is not included in the article's Creative Commons licence and your intended use is not permitted by statutory regulation or exceeds the permitted use, you will need to obtain permission directly from the copyright holder. To view a copy of this licence, visit http://creativecommons.org/licenses/by/4.0/.

\section{References}

Abd El-Kader M, Abdou MI, Fadl AM, Abd Rabou A, Desouky OA, El-Shahat MF. Novel light-weight glass-ceramic proppants based on frits for hydraulic fracturing process. Ceram Int. 2020;46(2):1947-53. https://doi.org/10.1016/j.ceram int.2019.09.173.

Bestaoui-Spurr N, Hudson H. Ultra-light weight proppant and pumping design lead to greater conductive fracture area in unconventional reservoirs. In: SPE Oil and Gas India Conference and Exhibition, Mumbai, India. 2017. https://doi.org/10.2118/185435-MS.

Bestaoui-Spurr N, Stanley D, Williams V, Usie M, Nguyen H, Hoffpauir E. Optimizing proppant surface properties to improve formation flow in offshore frac-packs. In: Offshore Technology Conference, Houston, Texas, USA. 2017a. https://doi.org/10.4043/27897 -MS

Bestaoui-Spurr N, Sun S, Williams V, Volk A, Nguyen S. Using properties in nature to modify proppant surfaces and increase flow. In: SPE International Conference on Oilfield Chemistry, Montgomery, Texas, USA. 2017b. https://doi.org/10.2118/184543-MS

Bicerano J. Method for the fracture stimulation of a subterranean formation having a wellbore by using impact-modified thermoset polymer nanocomposite particles as proppants. US Patent No. 8258083B2. 2012

Brannon HD, Starks TR. The effects of effective fracture area and conductivity on fracture deliverability and stimulation value. In: SPE Annual Technical Conference and Exhibition, Denver, Colorado, USA. 2008. https://doi.org/10.2118/116057-MS

Brannon HD, Starks TR. Maximizing return-on-fracturing-investment by using ultra-lightweight proppants to optimize effective fracture area: can less be more? In: SPE Hydraulic Fracturing Technology Conference, The Woodlands, Texas. 2009. https://doi. org/10.2118/119385-MS

Brannon HD, Kendrick DE, Luckey E, Stipetich A. Multistage fracturing of horizontal shale gas wells using $>90 \%$ foam provides improved production. In: SPE Eastern Regional Meeting, Charleston, West Virginia, USA. 2009. https://doi.org/10.2118/12476 7-MS

Chambers RW, Meise KD. Comparison of fracture geometries utilizing ultralightweight proppants provide evidence that partial monolayers can be created: a case history. In: SPE Annual Technical Conference and Exhibition, Dallas, Texas. 2005. https://doi. org/10.2118/96818-MS

Chen T, Wang Y, Yan C, Wang H, Xu Y, Ma R. Preparation of heat resisting poly (methyl methacrylate)/graphite composite microspheres used as ultra-lightweight proppants. J Appl Polym Sci. 2015. https://doi.org/10.1002/app.41924.

Chen Z. The application of light and ultra-light weight proppant in horizontal well sand control: unified model and case histories. In: SPE Deepwater Drilling and Completions Conference, Galveston, Texas, USA. 2012. https://doi.org/10.2118/147451-MS

Cheng F, Li Q. A study of formation damage of fracturing fluid. Nat Gas Ind. 2006;26(1):109-11 (in Chinese).

Coker CE, Mack MG. Proppant selection for shale reservoirs: optimizing conductivity, proppant transport and cost. In: SPE
Unconventional Resources Conference Canada, Calgary, Alberta, Canada. 2013. https://doi.org/10.2118/167221-MS.

Deng F, Li X, He L, Feng Y. Experimental evaluation of metal foam for sand control. J Pet Sci Eng. 2019;176:1152-60. https://doi. org/10.1016/j.petrol.2019.01.087.

Deng F, Sun D, Sun J, Wen M, Hu H, Xu Y, et al. Experimental simulation of erosion behavior of monolayer metal screen in sandstone reservoir. Eng Fail Anal. 2019;105:255-65. https://doi. org/10.1016/j.engfailanal.2019.06.098.

Fan J, Bailey TP, Sun Z, Zhao P, Uher C, Yuan F, et al. Preparation and properties of ultra-low density proppants for use in hydraulic fracturing. J Pet Sci Eng. 2018;163:100-9. https://doi.org/10.1016/j. petrol.2017.10.024

Feng K, Hung G-Y, Liu J, Li M, Zhou C, Liu M. Fabrication of high performance superhydrophobic coatings by spray-coating of polysiloxane modified halloysite nanotubes. Chem Eng J. 2018;331:744-54. https://doi.org/10.1016/j.cej.2017.09.023.

Fu L, Zhang G, Ge J, Liao K, Li T, Yu M. Study on a new waterinhibiting and oil-increasing proppant for bottom-water-drive reservoirs. J Pet Sci Eng. 2016;145:290-7. https://doi.org/10.1016/j. petrol.2016.05.025

Gao F, Cui B, Hou Z, Liu J. Ultra-low density proppant for low-permeability petroleum, coalbed methane and shale gas hydraulic fracturing and preparation method. China Patent No. CN105038759A. 2015 (in Chinese)

Gaurav A, Dao EK, Mohanty KK. Ultra-lightweight proppants for shale gas fracturing. In: Tight Gas Completions Conference, San Antonio, Texas, USA. 2010. https://doi.org/10.2118/138319-MS.

Gaurav A, Dao EK, Mohanty K. Evaluation of ultra-light-weight proppants for shale fracturing. J Pet Sci Eng. 2012;92:82-8. https:// doi.org/10.1016/j.petrol.2012.06.010.

Gong Y, Deng H, Luo W, Yan C. An ultra-low density proppant and preparation method. China Patent No. CN105062461A. 2015. (in Chinese)

Gu M, Dao E, Mohanty KK. Investigation of ultra-light weight proppant application in shale fracturing. Fuel. 2015;150:191-201. https://doi.org/10.1016/j.fuel.2015.02.019.

Guo Z, Liu W, Su B-L. Superhydrophobic surfaces: from natural to biomimetic to functional. J Colloid Interface Sci. 2011;353(2):33555. https://doi.org/10.1016/j.jcis.2010.08.047.

Guo Z, Yao X, Ma X. Preparation and properties of porous mullite base low-density high-strength proppants. Pet Drill Tech. 2013;41(2):39-43. https://doi.org/10.3969/j.issn.10010890.2013.02.008 (in Chinese).

Han J, Pirogov A, Li C, Hurt R, Sookprasong A, Min Kim J. Maximizing productivity with ultra-lightweight proppant in unconventional wells: Simulations and field cases. In: SPE Asia Pacific Hydraulic Fracturing Conference, Beijing, China. 2016. https:// doi.org/10.2118/181849-MS

Han X. Preparation and properties of modified polystyrene microspheres used as ultra-low density proppant. M.S. Thesis. Central China Normal University, 2015. (in Chinese)

Han X, Cheng Q, Bao F, Gao J, Yang Y, Chen T, et al. Synthesis of low-density heat-resisting polystyrene/graphite composite microspheres used as water carrying fracturing proppants. Polym Plast Technol Eng. 2014;53(16):1647-53. https://doi. org/10.1080/03602559.2014.919648.

He J, Yu L, Ye C, Li X. Parameter optimization of gravel packing sand control method for natural gas hydrate production. IOP Conf Series: Earth Environ Sci. 2018;153(2):022009. https://doi. org/10.1088/1755-1315/153/2/022009.

Hou M, Chen W, Jia Y. Novel ultra-low-density propping agent and preparation method. China Patent No. CN105176513A. 2015. (in Chinese) 
Jardim Neto AT, Prata FGM, Gomez J, Pedroso CA, Martins M, Silva DN. Ultralightweight proppants: an effective approach to address problems in long horizontal gravel packs offshore Brazil. SPE Drill Complet. 2012;27(04):613-24. https://doi. org/10.2118/150581-PA.

Jardim Neto AT, Prata FGM, Gomez JR, Pedroso CA, Martins MdO, Silva DN. Ultra-lightweight proppant technology: best practices for long horizontal gravel packs offshore Brazil. In: North Africa Technical Conference and Exhibition, Cairo, Egypt. 2012b. https ://doi.org/10.2118/150581-MS

Kendrick DE, Puskar MP, Schlotterbeck ST. Ultralightweight proppants: a field study in the big sandy field of eastern Kentucky. In: SPE Eastern Regional Meeting, Morgantown, West Virginia. 2005. https://doi.org/10.2118/98006-MS

Lester Y, Yacob T, Morrissey I, Linden KG. Can we treat hydraulic fracturing flowback with a conventional biological process? The case of guar gum. Environ Sci Technol Lett. 2014;1(1):133-6. https://doi.org/10.1021/ez4000115.

Li B, Li L, Huang Y, Zhang A. Preparation of resinified granulated walnut shell as fracturing proppant of ultralow density. Oilfield Chem. 2009;26(3):256-9. https://doi.org/10.19346/j.c nki.1000-4092.2009.03.007 (in Chinese).

Li B, Wang Y-F, Hu Y-L, Zhao Z-C, Shao W, Zhang A-M. Study on a low-density fracturing fluid proppant. Oilfield Chem. 2011;28(4):371-5. https://doi.org/10.19346/j.c nki.1000-4092.2011.04.005 (in Chinese).

Li S. Evaluation and application of ULW-10.5 ultra-low density proppant. Oil Gas Field Ground Eng. 2013;32(9):66-7. https://doi. org/10.3969/j.issn.1006-6896.2013.9.037 (in Chinese).

Liang C, Luo W, Yan C, Zhou Q, Gao Q, Duan P. Ultra-lightweight proppant synthesized from pmma/pine bark composite: low-cost material and outstanding properties. Chem Lett. 2016;45(8):9946. https://doi.org/10.1246/cl.160434.

Liang F, Sayed M, Al-Muntasheri G, Chang FF. Overview of existing proppant technologies and challenges. In: SPE Middle East Oil and Gas Show and Conference, Manama, Bahrain. 2015. https:// doi.org/10.2118/172763-MS

Liang T, Yan C, Zhou S, Zhang Y, Yang B. Carbon black reinforced polymethyl methacrylate (PMMA)-based composite particles: preparation, characterization, and application. J Geophys Eng. 2017;14(5):1225-32. https://doi.org/10.1088/1742-2140/aa6e7e.

Ma C, Deng J, Dong X, Sun D, Feng Z, Luo C, et al. A new laboratory protocol to study the plugging and sand control performance of sand control screens. J Pet Sci Eng. 2020;184:106548. https://doi. org/10.1016/j.petrol.2019.106548.

Ma R, Bo F, Gao J, Chen H, Hu P, Xu L, et al. A graphene modified ultra-low density proppant and preparation method. China Patent No. CN106833601A. 2017a. (in Chinese)

Ma R, Bo F, Gao J, Chen H, Hu P, Xu L, et al. An ion cross-linking modified ultra-low density proppant and preparation method. China Patent No. CN106753320A. 2017b. (in Chinese)

Man S. Compression and flow behavior of proppants in hydraulically induced fracture. M.S. Thesis. University of Calgary, 2016. https ://doi.org/10.11575/PRISM/25390.

Martch WE, Hudson AJ, Bode W, Fischer CC, Constien VG. Fundamentals of gravel pack performance with mesh screens. In: SPE International Symposium and Exhibition on Formation Damage Control, Lafayette, Louisiana, USA. 2012. https://doi. org/10.2118/151865-MS

Martins AL, de Magalhaes JVM, Ferreira MVD, Calderon A, de Sa AN. Sand control in long horizontal section wells. In: Offshore Technology Conference, Houston, Texas. 2009. https://doi. org/10.4043/20113-MS

Myers R, Potratz J, Moody M. Field application of new lightweight proppant in Appalachian tight gas sandstones. In: SPE Eastern
Regional Meeting, Charleston, West Virginia. 2004. https://doi. org/10.2118/91469-MS

Neog A. Investigating the potential of surfactants in improving the performance of stimulation fluids in ultra-tight shales. Master's Thesis, Texas A \& M University. 2014. http://hdl.handl e.net/1969.1/158900.

Neto J, Abrahao T, Prata FGM, Gomez J, Pedroso CA, Martins M, et al. Ultralightweight proppants: an effective approach to address problems in long horizontal gravel packs offshore Brazil. SPE Drill Complet. 2012;27(04):613-24. https://doi.org/10.2118/15058 1-PA.

Nguyen PD, Rickman RD, Weaver JD, Vonk TZ, Loghry RA. New treatment method for enhancing propped fracture conductivity-a laboratory study. In: SPE European Formation Damage Conference and Exhibition, Noordwijk, The Netherlands. 2013. https:// doi.org/10.2118/165173-MS

Nosonovsky M, Bhushan B. Superhydrophobic surfaces and emerging applications: non-adhesion, energy, green engineering. Curr Opin Colloid Interface Sci. 2009;14(4):270-80. https://doi. org/10.1016/j.cocis.2009.05.004.

Ojo KP. 3-D numerical simulation of horizontal well gravel pack. PhD Dissertation, University of Oklahoma, 2004.

Parker MA, Ramurthy K, Sanchez PW. New proppant for hydraulic fracturing improves well performance and decreases environmental impact of hydraulic fracturing operations. In: SPE Eastern Regional Meeting, Lexington, Kentucky, USA. 2012. https://doi. org/10.2118/161344-MS

Parmar JS. Displacement Of Water By Gas in Propped Fractures: Effect of Fracture Fluid Surface Tension, Viscosity, Proppant Wettability and Gravity. M.S. Thesis, University of Alberta, 2013. https://doi. org/10.7939/R3GQ6R83V

Parse JB, Jette BD. Multiple component neutrally buoyant proppant. US Patent No. 9051511.9. 2015a

Parse JB, Jette BD. Single component neutrally buoyant proppant. US Patent No. 9102867. 2015b

Pucknell JK, Mason JNE. Predicting the pressure drop in a cased-hole gravel pack completion. In: European Petroleum Conference, Cannes, France. 1992. https://doi.org/10.2118/24984-MS

Rediger R, Petrella J, Aron MJ, Fennell BW. Increasing buoyancy of well treating materials. US Patent No. 8058213. 2011

Rickards AR, Brannon HD, Wood WD, Stephenson CJ. High strength, ultra-lightweight proppant lends new dimensions to hydraulic fracturing applications. In: SPE Annual Technical Conference and Exhibition, Denver, Colorado. 2003. https://doi. org/10.2118/84308-MS

Rickards AR, Brannon HD, Wood WD. High strength, ultralightweight proppant lends new dimensions to hydraulic fracturing applications. SPE Prod Oper. 2006;21(02):212-21. https://doi. org/10.2118/84308-PA.

Schein GW, Carr PD, Canan PA, Richey R. Ultra lightweight proppants: their use and application in the Barnett Shale. In: SPE Annual Technical Conference and Exhibition, Houston, Texas. 2004. https://doi.org/10.2118/90838-MS

Sharma MM, Zhang R, Chenevert ME, Ji L, Guo Q, Friedheim J. A new family of nanoparticle based drilling fluids. In: SPE Annual Technical Conference and Exhibition, San Antonio, Texas, USA. 2012. https://doi.org/10.2118/160045-MS

Shrey S. Modifying proppant surface with superhydrophobic coating to enhance fracture conductivity. M.S. Thesis. University of Louisiana at Lafayette, 2018. https://search.proquest.com/dissertationstheses/modifying-proppant-surface-with-superhydrophobic/docvi ew/2207437625/se-2?accountid=145095

Shrey S, Mokhtari M, Farmer WR. Modifying proppant surface with nano-roughness coating to enhance fracture conductivity. In: SPE/ 
AAPG Eastern Regional Meeting, Pittsburgh, Pennsylvania, USA. 2018. https://doi.org/10.2118/191826-18ERM-MS

Song D, Daniello RJ, Rothstein JP. Drag reduction using superhydrophobic sanded Teflon surfaces. Exp Fluids. 2014;55(8):1783. https ://doi.org/10.1007/s00348-014-1783-8.

Stadulis JM. Development of a completion design to control screenouts caused by multiple near-wellbore fractures. In: Low Permeability Reservoirs Symposium, Denver, Colorado. 1995. https://doi. org/10.2118/29549-MS

Sun W-Y, Yao X. Performance of resin coated unburned ultralow density fracturing proppant. Bull Chinese Ceram Soc. 2015;34(10):2900-4. https://doi.org/10.16552/j.cnki.issn10011625.2015.10.030 (in Chinese).

Tabatabaei M, Dahi Taleghani A, Cai Y, Santos L, Alem N. Surface modification of proppant using hydrophobic coating to enhance long-term production. SPE Prod Oper. 2020. https://doi. org/10.2118/196067-PA.

Trujillo H, Tengono JA, Hernandez AE, Ortiz Prada E, Charry WM, Castaño R, et al. Long horizontal gravel pack with the lightest gravel ever used. In: SPE Latin American and Caribbean Petroleum Engineering Conference, Lima, Peru. 2010. https://doi. org/10.2118/138589-MS

Trujillo H, Tengono JA, Rubiano J, Castaño R, Beltran A, Ortiz E, et al. How to deliver $100 \%$ packing efficiency in openhole gravel packs: a field study in Colombia. In: SPE Annual Technical Conference and Exhibition, Denver, Colorado, USA. 2011. https://doi. org/10.2118/146447-MS
Valko P, Economides MJ. Foam proppant transport. SPE Prod Facil. 1997;12(04):244-9. https://doi.org/10.2118/27897-PA.

Wang C, Zhang K, O’Neil B, Lu W, Quintero H. Proppant upgrade by wettability alteration. In: International Petroleum Technology Conference, Bangkok, Thailand. 2016. https://doi.org/10.2523/ IPTC-18802-MS

Weaver JD, Nguyen PD. Hydrophobic filming reduces frac gel and mineral scale damage. In: SPE Eastern Regional Meeting, Morgantown, West Virginia, USA. 2010. https://doi.org/10.2118/13831 4-MS

Willberg D, Fredd CN, Goloshchapova DA, Makarychev-Mikhailov SM. Hydraulic fracturing proppants. Google Patents. 2015. US8991494B2

$\mathrm{Wu}$ Y. Influence of mineral additives on the properties of fracture proppant. M.S. Thesis. Taiyuan University of Technology, 2013.

Yamamoto M, Nishikawa N, Mayama H, Nonomura Y, Yokojima S, Nakamura S, et al. Theoretical explanation of the lotus effect: superhydrophobic property changes by removal of nanostructures from the surface of a lotus leaf. Langmuir. 2015;31(26):7355-63. https://doi.org/10.1021/acs.langmuir.5b00670.

Zhang Y, Yan C, Chen T, Wang Y. Ultra-lightweight composite proppants prepared via suspension polymerization. J Compos Mater. 2016;50(20):2823-31. https://doi.org/10.1177/002199831561312 8.

Zhou S, Sun F. Sand production management for unconsolidated sandstone reservoirs. Wiley Online Library, New York. 2016. https:// doi.org/10.1002/9781118961865. 